\title{
Energy Productivity in the Industrial Sector: An Econometric Analysis
}

\author{
J. M. Roop
}

January 1983

Prepared for the U.S. Department of Energy under Contract DE-AC06-76RLO 1830

Pacific Northwest Laboratory Operated for the U.S. Department of Energy by Battelle Memorial Institute 


\title{
DISCLAIMER
}

This report was prepared as an account of work sponscred by an agency of the United States Government. Neither the United States Government nor any agency thereof, nor any of their employees, makes any warranty, express or implied, or assumes any legal liability or responsibility for the accuracy, completeness, or usefulness of any information, apparatus, product, or process disclosed, or represents that its use would not infringe privately owned rights. Reference herein to any specific commercial product, process, or service by trade name, trademark, manufacturer, or otherwise, does not necessarily constitute or imply its endorsement, recommendation, or favoring by the United States Government or any agency thereof. The views and opinions of authors expressed herein do not necessarily state or reflect those of the United States Government or any agency thereof.

\author{
PACIFIC NORTHWEST LABORATORY \\ operated by \\ BATTELLE \\ for the \\ UNITED STATES DEPARTMENT OF INERGY \\ under Contract DE-AC06-76RLOO 1830
}

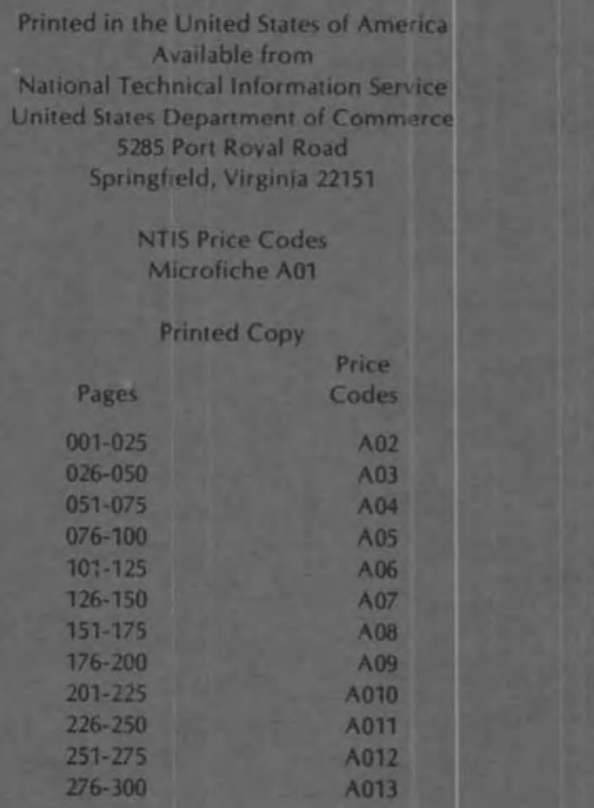




\section{4}

PNL -4596

IJC-98F

ENERGY PRODUCTIVITY IN THE INDUSTRIAL

SECTOR: AN ECONOMETRIC ANALYSIS

J. M. Roop

January 1983

Prepared for

the U.S. Department of Enerqy

under Contract DE-AC06-76RLO 1830

Pac if ic Northwest Laboratory

Richland, Washington 99352 


\section{SUMMARY AND CONCLUSIONS}

This study examines aspects of enerqy productivity and energy intensity with in the industrial sector of the economy. Our results suggest that relative prices and other economic factors can explain much of the variation in both energy productivity and energy intensity for manufacturing and mining and for the industrial sector as a whole. Cyclical factors, seasonal factors and trend variables are also useful in explaining variation in these data, both for annual and monthly time series. Of the variables examined, it appears that the relative price of energy is a highly significant factor in accounting for the difference between actual industrial enerqy intensity and that which might have been expected had pre-1973 trends continued.

But these findings te 11 on $1 y$ a small part of a larger story. There is consistent evidence, statistically, that these relationships are not adequately spec ified. And this finding is further supported by a review of the literature. At the same time that relative energy prices were rising sharply, many other events were simultaneously occurring that could cause multiple interpretations of the same data--price controls were being eased, requirements for pollution abatement investments were being promulqated, multinational companies were shifting production to lower-cost countries, to name but a few of these compounding factors. Moreover, our results are descriptive, at least in part, rather than causal. Although rising energy prices likely caused some of the changes that occurred, how these changes were brought about requires that we pursue the analvsis at the level of the economic agent making the decision, rather than relying on descriptive analyses of changes that occur.

Viewed from this perspective, energy productivity could change as a result of individual firms implementing more efficient practices or shifts in industrial output from less to more energy-efficient industries. This latter change could occur as a result of consumers' choice or through producers using less of those inputs that have a high energy component, or through the substitution of imports for industrial products with high energy content. The 
choices of these economic agents would then also explain, at least in part, how energy intensity within the industrial sector had changed.

This is a topic for further research. The results of this study clearly suggest that such work needs to be done. 


\section{CONTENTS}

SUMMARY AND CONCLUSION

1.0 INTRODUCTION

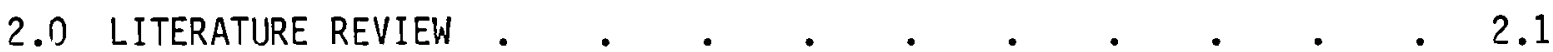

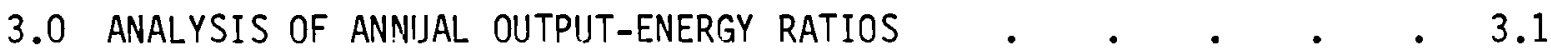

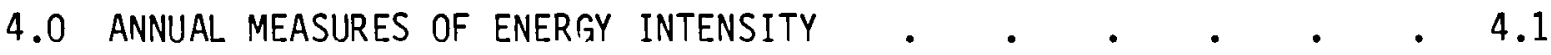

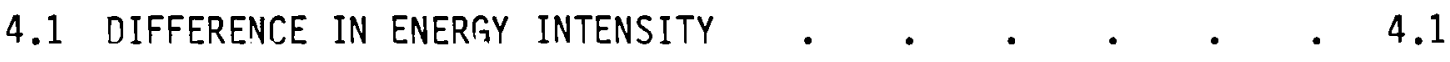

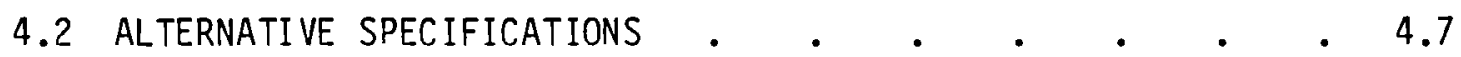

4.3 DECOMPOSITION OF EFFECTS $\quad . \quad \ldots \quad$. $\quad . \quad \ldots \quad$. 4.13

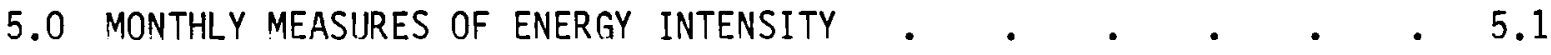

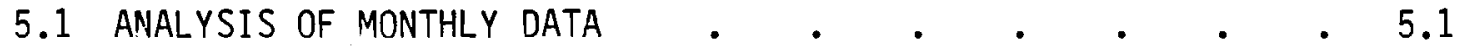

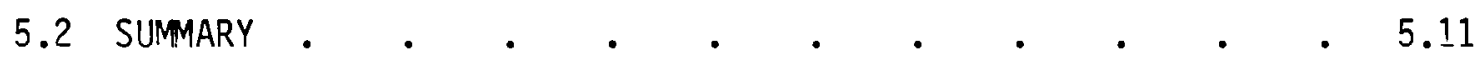

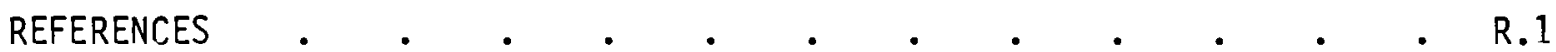

APPENDIX: DATA DESCRIPTION 


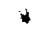

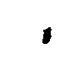




\section{FIGURES}

4.1 Actual and Trend Values for Explanatory Variables . . . 4.14

4.2 Actual, Trend and Forecast for Difference

in Output-Energy Ratios . . . . . . . . . . 4.16

4.3 Actual, Trend and Forecast for Ratio of Industrial
Production Indexes. $. . \quad . \quad . \quad . \quad . \quad . \quad 47$ 
-

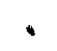




\section{TABLES}

3.1 Regression Results Using Dutput/Enerqy Ratios . . . . . 3.3

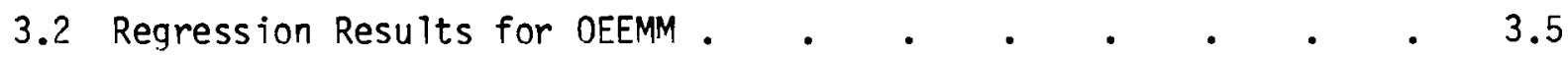

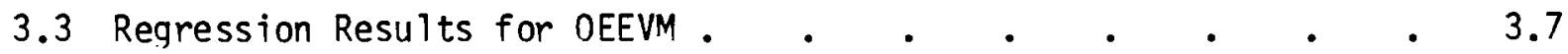

4.1 Ordinary Least Squares Regression Results for

4.2 Ordinary Least Squares Regression Results for DIFF--Three Explanatory Variables and TIME . . . . . 4.5

4.3 Further DIFF Regression Results--Correction for Serial Correlation . • . . . . . . . . . . 4.6

4.4 PLOT and Decomposition of Regression Results

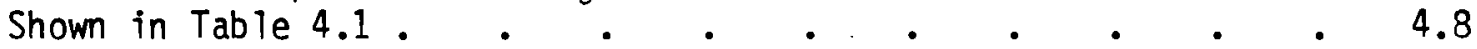

4.5 Regression of RATIOEV Against Three Explanatory Variables . $\quad 4.9$

4.6 PLOT and Decomposition of Regression Shown in Table 4.5 . 4.11

4.7 Regressions of Percentage Differences Against Three Explanatory Variables . . . . . . . . . . . 4.12

5.1 Regression of Month Ty OEEMM Against Three Explanatory
Variables and Monthly Dumy Variables . . . . . . . . 5.3

5.2 Monthly Regression of OEEMM Correcting for Serial Correlation . • . . . . . . . . 5.5

5.3 Monthly Regression of OEVMM Against Three ExDlanatory Variables and Monthly Dummy Variables . . . . . . 5.7

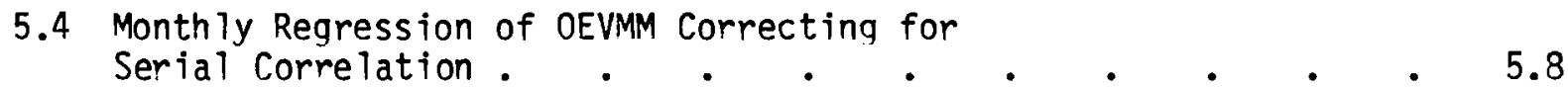

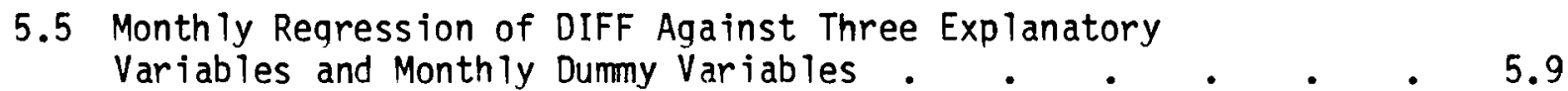

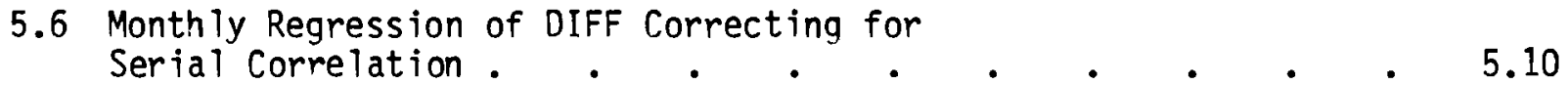

A.1 Revised Variables Used in Annual Marlay Regressions . • . A.2

A.2 Revised Variables Used in Monthly Marlay Regressions
November 1982 
$\checkmark$

$\bullet$ 


\subsection{INTRODUSTIION}

The major obiective of this study is to estimate the relative importance of factors that influence eneray productivity in the industrial sector of the economy--especially manufacturing and mining. Among these major factors, we have selected changing relative prices, investment, and cyclical/seasonal phenomena as variables of interest in explaning changes in energy productivity as measured by output-eneray ratios. The impact of these factors is examined using regression analys is on both annual data from 1954 to 1980 and monthly data from 1973 to 1980. The focus is on two measures of energy productivity: an output-eneray ratio that applies value-added weights to the index of output and this same ratio applying energy consumption measures as weights. Shifts in energy intensity of the industrial sector examined are measured by the differences between these ratios and the ratio of energy weighted to valueadded weighted output. These further measures are indicators of the shift in energy intensity of industrial output.

Shifts in the energy intensity of industrial output may occur as a result of many factors. Among these are the growth in income and output, changing relative factor and final goods prices, competition from abroad, shifts of material-intensive industries to locations outside the country, seasonal factors, and changes in production technologies. This study concentrates on only three of these factors. Using annual data, the three factors are 1) the relative price of energy, 2) the cyclical influence of output growth represented by the level of capacity utilization, and 3 ) the influence of technological change as represented by the ratio of new investment to the total capital stock or a time trend. In the analysis that uses monthly data, the influence of technology is dropped, since its effects are neither very short term nor available on a monthly basis, and seasonal factors are substituted. These static regression analyses allow us to disaggregate the influence of each factor on different measures of energy intensity in the industrial sector.

The analysis begins by reviewing other studies to assess the measured causes of changes in energy intensity with in the industrial sector. This 
review indicates that little empirical work has been done that measures either the changes that have occurred or the causes of these changes. The third section begins the annual analysis; regression results that sort out the separate influences of three variables on different measures of output-eneray ratios are reported. The fourth section then analyzes alternative measures of the change in enerqy intensity, using these same three factors. This analysis includes a decomposition of the separate influences of energy price changes, cyclical, and technological factors. The fifth section reports on the analysis of monthly measures of output-energy ratios. This section provides evidence on the magnitude of the seasonal factors that influence energy consumption. The final section gives our conclusions, and highlights research topics that need further studv. An appendix describes the data used in the analysis. 


\subsection{LITERATURE REVIEW}

In this brief review, our attention will focus primarily on studies that have some bearing on the questions addressed in this paper. Specifically, what factors are associated with changes in eneray intensity within the industrial sector and how do these factors affect energy efficiency. Limiting the scope of these issues also limits the range of literature reported on, since few writers address these issues directly. But a side issue relating to one of these factors, namely energy prices, is integral to the discussion -- what is the approximate magnitude of the price elasticity of the demand for energy.

We take for granted that this elasticity is negative -- an increase in the price of energy causes a decline in the quantity demanded. Beyond this statement, the evidence is less than overwhelming. Yet this elasticity is important for assessing the sensibility of our results: if demand is inelastic (and most would aqree it is), then sharp increases in price will have relatively less of an effect on demand. But by how much? We will return to this question later. We begin by first reviewing studies of industrial energy demand, which leads into the elasticity question. We conclude th is section with a brief look at the macroeconomic studies that measure the impact of oil price increases on the economy as a whole.

A Department of Commerce study from the Bureau of Industrial Economics (BIE) by Kristensen and Correia (1980) examined eight 4-digit manufacturing industries that account for 60 percent of total manufacturing energy consumption, but only 8 percent of value added. They note that factors that affect eneray efficiency can be either outside the control of the industry-cyclical fluctuations in demand, changes in product mix induced by demand, or changes required by legislative fiat--or subject to the ir control--elimination of waste, interfuel substitution, implementing new technologies and recycling scrap materials. The study covered the years 1971 and 1974 to 1977.

The general tenor of the study by Kristensen and Correia is that every industry has its special case. For example, paper and paperboard production shifted from recycled paper to virg in fiber final products, which are more enerqy intensive, as a result of shifts in demand. This shift occurred even 
though the price of enerqy over this period rose substantially. But offsetting th is, wood wastes have been increasingly substituted for purchased energy, thus raising the purchased eneray efficiency of these industries. Fuel switching in cement, on the other hand, has reduced the energy efficiency of th is industry since using the coal process requires more Btu's to produce the same amount of output.

On balance, these eight industries have increased their energy efficiency over the period 1971 to 1977. Although energy use increased 0.1 percent per year from 1971 to 1977, value added grew at a much faster rate (3.1 percent per year), so enerqy consumption per dollar of output declined 2 percent per year. This is less than for manufacturing as a whole (energy use per dollar of value added declined 3.2 percent per year) but greater than for the national economy as a whole (1.2 percent per year). These results are in close agreement with measures of energy efficiency reported by Belzer and Roop (1981).

Hirst et a1. (1981) look at the role of improved eneray efficiency in energy-use patterns since the sharp escalation of eneray prices in 1973 . In the industrial sector, energy consumption grew at the rate of 2.9 percent per year from 1950 to 1972; from 1973 to 1980, it grew at a rate of 0.4 percent per year. The energy-output ratio declined about 10 percent from 1973 to 1980, nearly double its historical rate. "This improvement in industrial energy efficiency is made up of two components; increases in energy efficiency of individual processes and changes in the composition of industrial output ... ." (D. 28-29) Ouoting Marlay (see below, D. 2.4), Hirst arques that about "half the reduction in 1980 energv intensiveness (relative to historical trend) was due to efficiency improvements and the remainder was due to changes in product composition." (p. 30)

The Hirst study asserts that 1980 industrial enerqy use was about 10 Ouad less than it would have been had historical trends continued. Half of the reduction was due to slower economic growth, one-quarter to changes in the mix of industrial output and one-quarter to improvements in energy efficiency. of the improvements in efficiency, about three-quarters was due to a continuation of historical trend, the remainder to additional improvements (see Hirst's Table 13). It is not clear how these numbers were arrived at, although there 
is an explanation of how total energy demand was obtained. It is worth examining the method of Hirst and his associates, as reported in Hirst's Appendix $B$, since the work to follow takes a considerably different tack.

The decomposition of enerqy consumption used by Hirst et al. is based on a linear model that explains energy use as a function of GNP, energy prices and time (and sometimes a lagged dependent variable). In another variant of this equation, the energy-output ratio is a linear function of energy prices and time. Based on estimated coefficients from the latter version of the equation, a GNP growth rate of 4.2 percent and trend enerqy prices were substituted to determine baseline forecasts of energy consumption had trends continued. These trend projections use the estimated equation with the lowest energy price elasticities of all those reported in Hirst's Table B.2: -.07 (the range is from -.24 to -.07 with a mean of -.13 ).

There are a number of problems with this equation, not the least of which is the low energy price elasticity. Hirst notes that the Stanford Energy Modeling Forum reports a mean price elasticity of -.5 . But there is additional evidence that the price elasticity is higher than that reported by Hirst. Berndt and Wood (1981) report price elasticities that range from -.8 to -.3 , with an average elasticity of -.58 . Magnus (1979) reports elasticities for the U.S. that range from -.79 to -.49 . Anderson (1980) reports elasticity measures from -.5 to -.42 for work done by others, although he argues that when intermediate materials are properly taken into account, the elasticity drops to about -.2. So the preponderance of evidence suggests that the Hirst's estimates are too low. There are other difficulties with this simple model apart from the low price elasticity.

Economic theory suggests that demand for a commodity depends on its relative price, the relative prices of competing and substitute commodities, income and other variables that might influence taste. As best one can determine from Hirst's Appendix B.2, the demand for energy is a function of income (GNP), the absolute (not relative) price of energy, and time. Since substitution effects in both consumption and production are contingent on the relative price of energy, this formulation suffers from the use of an inappropriate price measure. (But in fairness, a plot of the relative prices 
used in Section 4.1, compared with the Hirst prices, show only minor differences--smaller increases in 1976, a decline in 1978 for the relative prices, for example--but in a rearession analysis, these differences might be critical.)

There are a number of other studies that have only little direct bearing on the questions addressed in this paper, but are mentioned in passing. Mork and Hall (1980a, 1980b) have expanded a small macroeconomic model with an energy sector to examine the policy questions related to response to sharp increases in exogenous energy prices. The major weakness of this model, and one which makes the results highly suspect, is that it is unstable. A more recent study by Darby (1982), looks at the output impacts of changing eneray prices using a model that consists of several small macroeconomic models. He notes that determining the output effects in isolation is difficult since a number of other events were also occurring as prices rose. Darby concludes that further work needs to be done to determine how oil price shocks affect economies.

One author has made a significant contribution to the questions addressed in this report--Robert C. Marlay (1981a, 1981b, 1982). His contributions to this report are more than just indirect. The cautionary conclusion of Section 4.0 is a direct result of suggestions from Marlay (1982) and conversations with the author. More directly, the data used in this analys is and described in the Appendix comes directly from Marlay's unpublished dissertation research. The completion of this dissertation is expected, and, thus, the data will be available this summer. 


\subsection{ANALYSIS OF ANNUAL OUTPUT-ENERGY RATIOS}

Econometric analysis of the output-energy ratios (OER) is based on the proposition that the ratios are behavioral functions of economic and noneconomic factors. A significant portion of the economic environment is represented by: a variable for relative energy prices (RELPR), the ratio of new investment to capital stock (RATIO), and capacity utilization (CU). The behavioral links between each of these explanatory variables and the OER is straightforward. As the relative price of energy increases, business will economize on its use; thus output per unit of energy will also increase. We also expect that as capacity increases, the ratio of output to energy will increase since the fixed energy consumption (e.g., in heating plants) is spread over more production, lowering the energy content of each unit of output. As investments are made that improve the energy efficiency of the capital stock, output per unit of energy should increase. But investment may not all be energy saving; labor saving or pollution abatement control investment may well be energy using, thus increasing the energy content of output. So the relationship between the RATIO variable and OER is ambiguous. But a positive relationship between the other environmental variables, RELPR and CU, and the output-energy ratio is expected.

Economic reasoning and statistical training suggest that we add a caveat at this point. We expect that the interrelationship between explanatory variables is strong. Relative energy price increases stimulate new investment to conserve energy use, suggesting a positive correlation between RELPR and RATIO. Investment is rarely undertaken when business conditions suggest that the new equipment will not be fully used -- a positive correlation between RATIO and CU. With movements of all these variables correlated, we can anticipate some statistical difficulty discriminating among influences. We might circumvent this problem by introducing another measure of technological change, for example, a time trend. We label these explanatory variables TIME and TSQ: the first is introduced to capture any linear influence that technological advance may have, the latter in the event that nonlinear effects may be significant. But we caution that problems may still remain. Among 
those that can be anticipated are problems because of the intercorrelation of explanatory variables and problems because there may be lags in effects of changes in explanatory variables that take longer than a year to resolve. Having pointed out this problem, we now turn to the regression results.

Table 3.1 sumarizes the major results of our regression analysis. Columns (1) $-(5)$ show the results using the energy weighted OER for manufacturing and mining (OEEMM). For example, colum (1) reports the regression using a constant term, RELPR, CU and RATIO. This formulation explains about 70 percent of the total variation in the OEEMM, with all explanatory variables except RATIO significant at the 5 percent level ( $t$-values are in parenthesis under the estimated coefficients). Overall, the regression is encouraging, but a number of unsatisfactory aspects are evident. The sign of the RATIO term suggests one of two things: either investments have been energy using or, more likely, it is a reflection of the fact that all three of the explanatory variables move coincidentally. A more disturbing aspect of this regression is that the DurbinWatson (D-W) statistic is very low -- an indication of positive serial correlation in the residuals. A statistical correction for this problem, devised by Cochrane and 0rcutt (explained in any introductory econometric textbook), is used in the regression reported in column (2). Although decidedly better (higher corrected R-squared, improved $D-W$ statistic), we must ask if there is an alternative specification of the equation that will alleviate the low D-W statistic without appealing to this correction procedure. Colums (3) and (5) explore this option by including TIME and TSQ as explanatory variables in the estimated equation.

Colum (3) reports the regression that introduces a linear trend in time. It shows a significant improvement compared to the regressions shown in columns (1) and (2). The significance of CU improves dramatically, RATIO now enters with a positive sign, and all variables are significant at the 1 percent confidence level. The percentage of explained variation improves to over 98 percent of the total, which indicates a "tight" fit. And the D-W statistic is now close enough to its expected value that we can reject the possibility of positive serial correlation of the residuals; a result achieved without appealing to the correction procedure of Cochrane and Orcutt. This regression 
TABLE 3.1. Regression Results Using Output/Energy Ratios

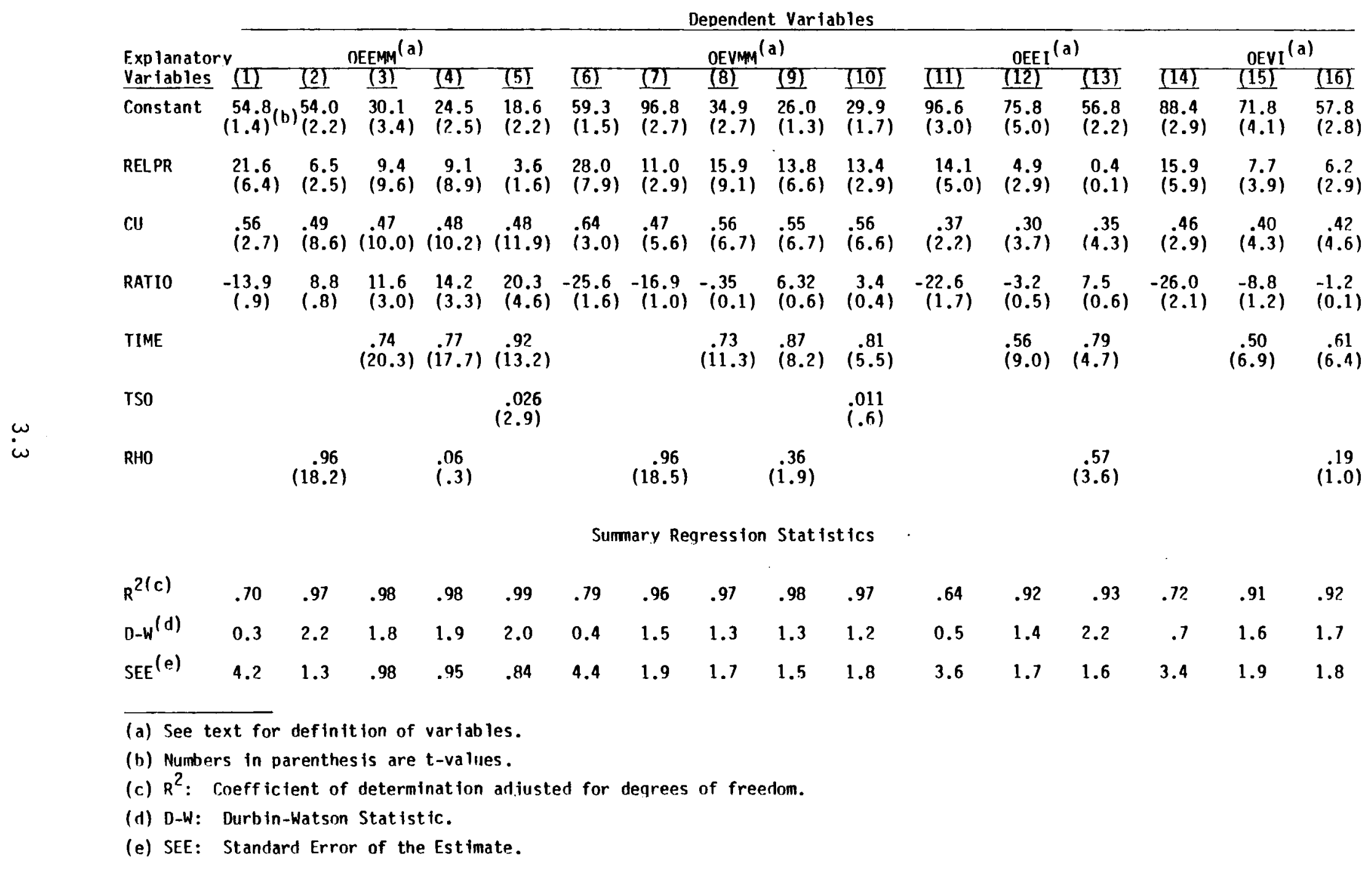


has been repeated on Table 3.2. Beneath the regression output is a plot of the actual and fitted values over the sample period, with a residual plot on the right side. The regression errors are outside a narrow (.98) SEE band on six occasions: in 1954, 1957, 1959, and 1978-1980.

The responsiveness of the OER to the explanatory variables can be calculated using the average values of the variables and the estimated coefficients. These calculated response coefficients, called elasticities, indicate the percentage change of the OER for a fixed percentage change in one of the explanatory variables. Using the equation shown in Table 3.2, for example, a 10 percent increase in the explanatory variables would increase the OER by 1 percent for RELPR, 4 percent for CU, and 2 percent for RATIO. The coefficient for TIME suggests that the OER will improve at the rate of about 0.7 percent per year as a result of technological improvements and other trend factors.

Colums (4) and (5) of Table 3.1 show two further regressions using OEEMM as the dependent variable. Column (4) applies the Cochrane-0rcutt correction to the regression of Column (3), and, as we would expect, shows little improvement. The first order serial correlation coefficient, RHO, is insignificant, and the coefficients are little changed in either magnitude or significance. Column (5) adds a quadratic in time, TSQ, to the regression of Colum (3), to check for the significance of nonlinearities in technological change. On balance, this specification is not an improvement. The coefficient on RELPR is much smaller and loses its significance. This most likely occurs because of the sharp increase in relative energy prices since 1973, coupled with a declining trend in energy prices in the early part of the sample period. The quadratic in time, which exaggerates this pattern, now enters significantly as an explanatory variable and removes the significance of the relative price term. On the basis of statistical parsimony, we reject both of these specifications.

Colums (6) $-(10)$ of Table 3.1 repeat these five regressions using the valueadded weighted OER (OEVMM) as the dependent variable. In some respects, the results are similar. Without a time trend, the results are unsatisfactory and are only modestly improved after correcting for serial correlation in the 
TABLE 3.2. Regression Results for OEEMM

DKDTNAFY LEAST SQUAFES

WFIIAELES...

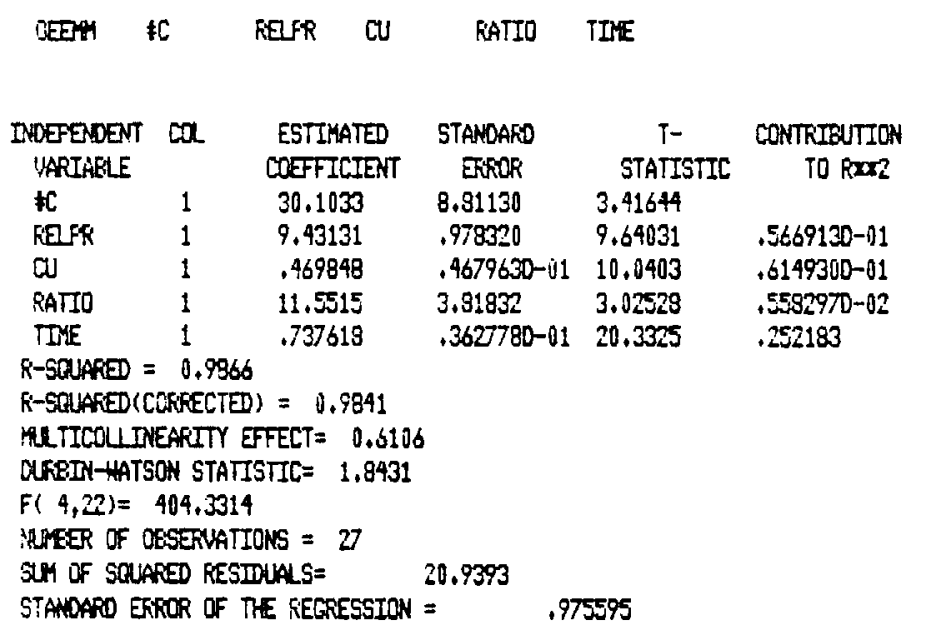

ACTUAL VALLES FLOTIED HITH $(t)$ FITTED VALLES PLOTTED NITH (I)

RESIDLALS PLOTTED WTHH (D) LINES AT + AND - .9756
ACTUAL VALLES FITIED VALLUES

89.7585
92.6575
92.3362
91.5944
89.7228
95.4872
93.7385
94.1806
96.4676
97.6440
98.8135
101.790
102.089
100.000
100.566
102.123
98.5900
99.7573
103.463
105.527
107.715
103.733
108.323
110.423
115.104
116.976
115.345

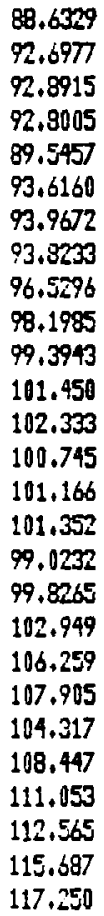

$\mathbf{x}$

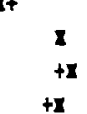

$\times$

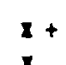

$\mathbf{x}$

$x$
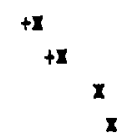

$+\mathbf{x}$

$x+$

$\mathbf{r}$

$+x$

$\mathbf{x}+$

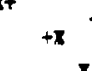

$+2$

$x$

$x$

$+x$

$\mathbf{x +}$

$x+$

$+\quad 1-1.40521$
RESIIUAS

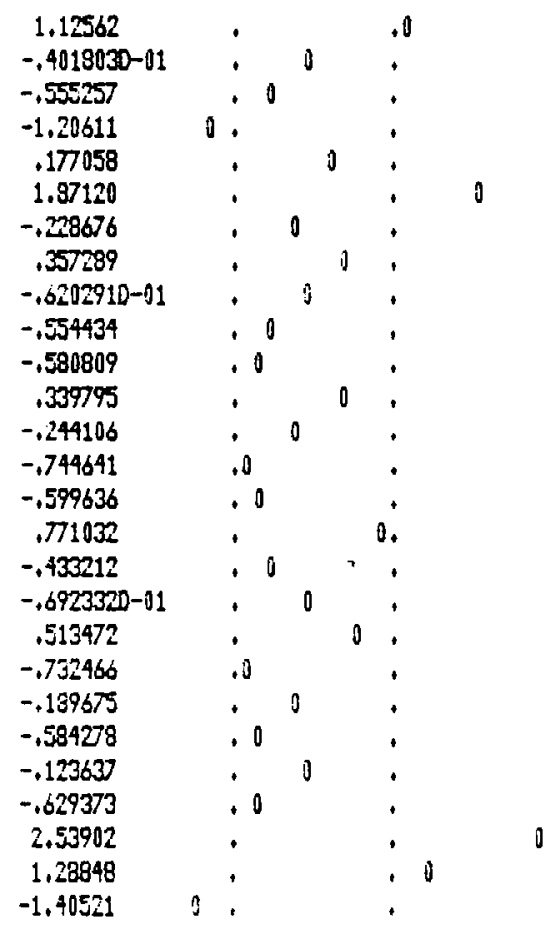


residuals. Adding a quadratic in time does not significantly improve the regression fit, although in this case the relative price term is not so adversely affected. But there are also some noticeable differences from those reported earlier. The coefficients on both capacity and relative price are uniformly higher. These higher coefficients and a lower average value for OEVMM raise the responsiveness of the OER to changes in RELPR and CU. Based on the regression reported in Colum (8) -- and shown in more detail in Table 3.3 - a 10 percent increase in the explanatory variables would increase OEVMM by 2 percent for RELPR and 5 percent for CU. These are somewhat higher than in the energy weighted OER regressions. It is also worth noting that the ratio of new investment to capital stock is not a significant explanatory variable in these regressions. These differences suggest that the question of the energy intensity of the industrial sector be examined in an alternative way, which we do in Section 4.0. But before turning to this question, we look briefly at broader measures of the OER for the industrial sector.

Columns (11)-(13) and (14)-(16) show regressions of our explanatory variables and time on broader measures of the OER for the entire industrial sector--including agriculture (OEEI and OEVI). Using the energy weighted OER for the entire industrial sector, OEEI, the major difference appears to be the lack of improvement in the $D-W$ statistic when time is introduced. When the Cochrane-0rcutt correction is made, the relative price term loses significance. For OEVI, the value-added weighted OER, the major difference is that the sign of RATIO is uniformly negative, although insignificant in Columns (15) and (16). These equations suggest that the estimated results discussed previously are fairly robust with respect to this set of data. 
TABLE 3.3. Regression Results for OEVMM

OFODNAFY LEAST SQLARES

VARTABLES. ..

DEVYI HC REPR OJ RATIO TIFE

\begin{tabular}{|c|c|c|c|c|c|}
\hline $\begin{array}{l}\text { THDEPEDENT } \\
\text { UARIABLE }\end{array}$ & ca & $\begin{array}{l}\text { ESTIMATED } \\
\text { COEFICIEMT }\end{array}$ & $\begin{array}{c}\text { STAMAARO } \\
\text { EFFOR }\end{array}$ & $\begin{array}{c}\text { T- } \\
\text { STATISTIC }\end{array}$ & $\begin{array}{c}\text { CONTRIBUTION } \\
\text { TO RmX }\end{array}$ \\
\hline tc & 1 & 34.8873 & 15.7291 & 2.21814 & \\
\hline REPR & 1 & 15.9116 & 1.74630 & 9.11161 & .101838 \\
\hline a & 1 & .556396 & $.8553130-01$ & 6.66092 & $.5442350-01$ \\
\hline RATIO & 1 & -.345912 & 6.81570 & $-.5075230-01$ & $.3159580-05$ \\
\hline Tres & 1 & .730987 & $.6475580-01$ & 11.2883 & .156307 \\
\hline
\end{tabular}

R-SOUARE $=0.9730$

$R$-SALFED (COFAECTED) $=0.9681$

MLICOL DKARTT EFFECT $=0.6604$

ORRBDH-WATSON STATISTIC $=1.2865$

$F(4,22)=198.3084$

MURER OF OESERUATIONS $=2$

SUY OF SRLARED RESDULLS= 66.7171

STANOARD ERROR OF THE RECRESSTON = 1.74143

ACTUAL VALLES PLOTTED HTTH ( + )

FITIED UALES PLOTTED HITH (I)
RESIDUALS PLOTTED NTTH ( 0 ) LDES AT + AND - 1.741
ACTUAL WALLES FITTED VALLES

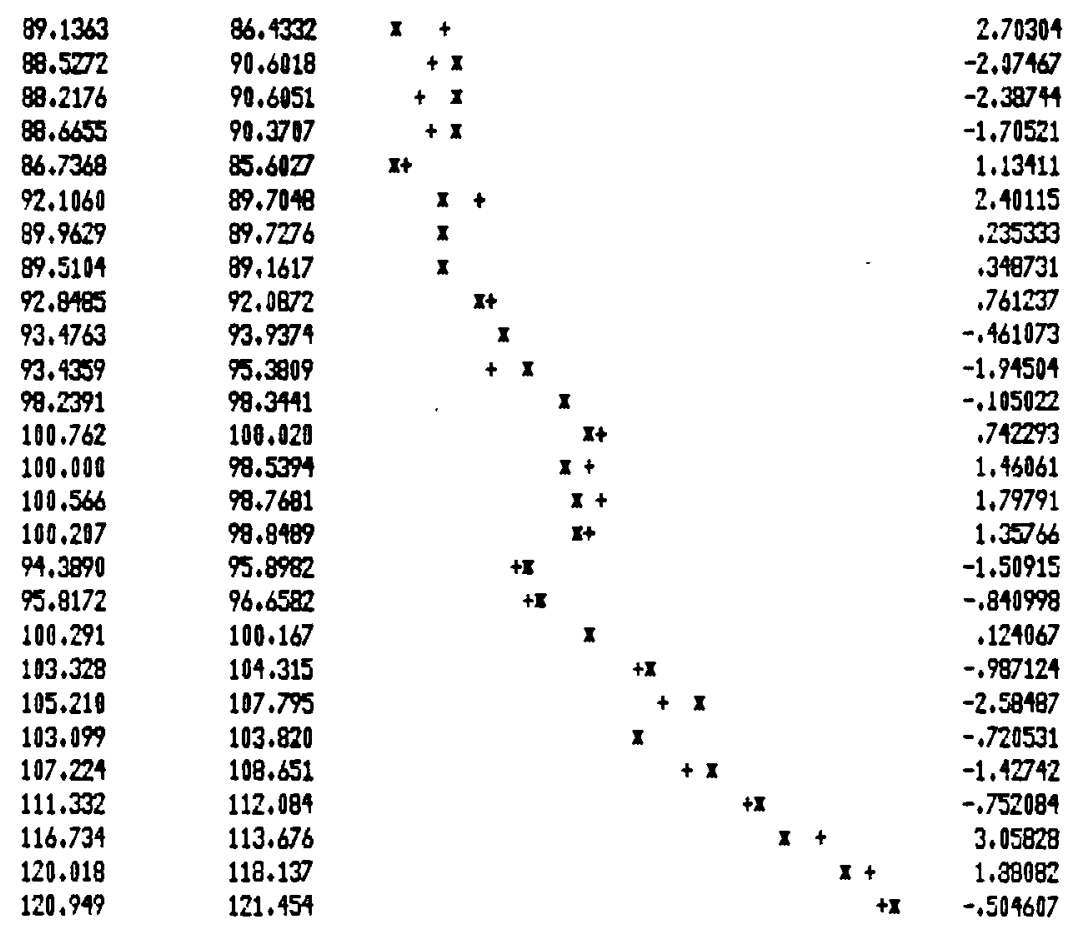

RESDUUAS

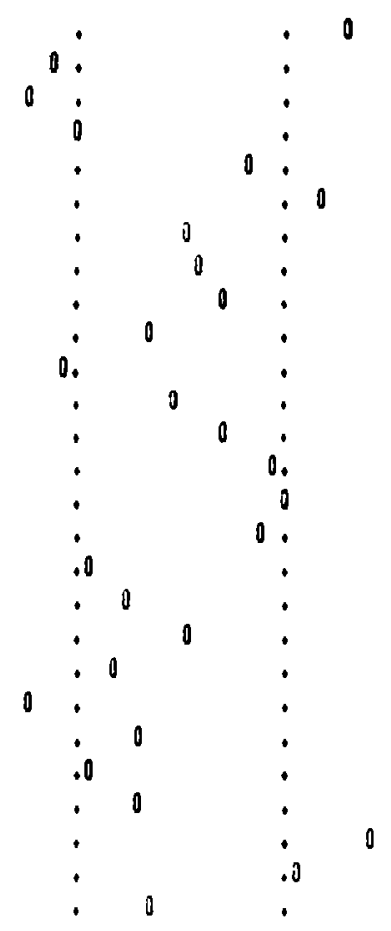





\subsection{ANNUAL MEASURES OF ENERGY INTENSITY}

A number of energy intensity measures can be conceived, based on the valueadded and energy weighted measures of output used before. The difference between the two output-energy ratios would be one such measure. But these differences provide no relative reference--is this period's change large or small relative to the current level? Percentage changes and ratios of OERs provide an alternative measure of the relative changes in energy intensiveness of the industrial sector. We begin by analyzing the differences between the energy weighted OER and the value-added weighted OER; we title this variable DIFF. Since total energy is the same in both cases, subtracting the two yields a measure of the difference in output per unit of energy use that can be attributed directly to differences in weights applied to the output index. In subsection 4.1 , this measure of energy intensity is investigated. In 4.2 , alternative specifications, riamely percentage changes and ratios, are examined. There appears to be little substantive difference in the conclusions that one draws from these alternative measures. In 4.3 , changes in energy intensity that actually occurred are compared with those that might have been reasonably expected if the explanatory variables had continued to follow trend values. This final section allows the decomposition of the total shift into components attributable to changes in energy price, to changes in other factors, and to a residual.

\subsection{DIFFERENCE IN ENERGY INTENSITY}

Before examining the regression results, it is worth reviewing the ways that changes in the explanatory variables might influence each of the outputenergy ratios, and thus, the differences in these ratios (DIFF). An increase in the relative price of energy would lead to economizing in the use of energy, thus increasing output per unit of energy, no matter how the output measure was weighted. However, since rising relative energy prices would cause the price of energy-intensive output to increase proportionately more than other output, consumers would shift away from these outputs or other industries would use less of them as intermediate goods. Thus, the energy weighted output measure would increase less than would the value-added measure. Hence the difference, 
TABLE 4.1. Ordinary Least Squares Regression Results for DIFF--Three Explanatory Variables

EXECTION STARTED

OFOINAFY LEAST SQLAPES

VAFIABLES...

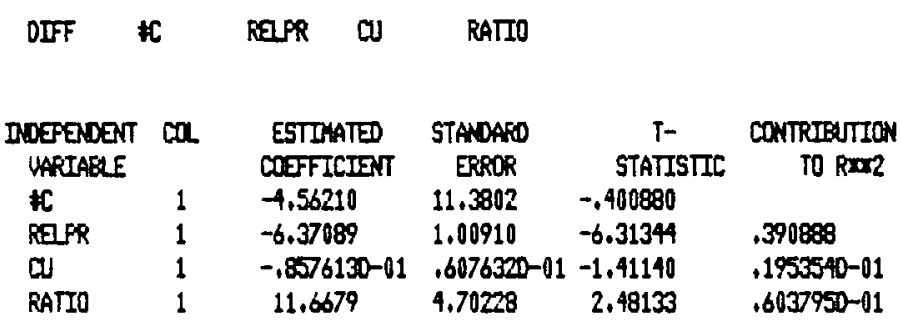

R-SRUAED $=0.7744$

R-SDUAFED (COFRECTED) $=0.7450$

AUTCOL INEARITY GPECT $=0.3036$

OLRBDH-WTSOM STATISTIC $=1.1926$

$F(3,23)=26.3240$

MUEER OF OESERUATIONS $=27$

SUM OF SQUAFED RESTDUALS= 37.2231

STAMDARD EREOR OF THE FEERESSION =

1.27216

ACTUAL VALLES PLOTIED WTTH (t) FITED VALES PLOTTED VITH ( $(\mathbf{x})$
RESTOLALS PLOTTED KTTH (0) LINES AT + ANO - 1.272
ACTUAL VALES FITED VALLES

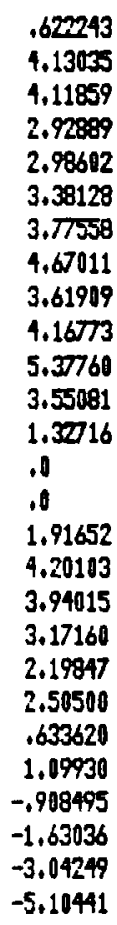

2.29900

2.16999

2,35139

2.4872

3.97314

3.92987

4.24658

4,65611

4,43111

4.24503

3.99415

3.09431

2,30921

2.28008

2.38262

2.48060

3.09001

3.12633

2,73665

1.90310

$.9630560-11$

.478167

$-.222900$

$-1.04357$

$-1.12987$

-2.45372
-4.18063
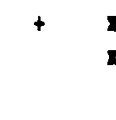

I

I+

$+\quad \mathbf{I}$

$+I$

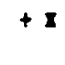

$+1$

I

I+

$+1$

I

$+1$

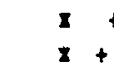

I +

It

x+

×

RESTIUAS

\begin{tabular}{|c|c|c|c|c|}
\hline-1.66176 & & 0. & & . \\
\hline 1.96036 & & . & & . \\
\hline $1.76 \sqrt{2}$ & & , & & . 0 \\
\hline .411617 & & . & 0 & . \\
\hline-.997118 & & .0 & & . \\
\hline-.548593 & & . 0 & & - \\
\hline-.471003 & & . & & - \\
\hline $.1399870-01$ & & . & 0 & - \\
\hline-.812013 & & . 0 & & . \\
\hline$-.7729610-01$ & & . & 0 & . \\
\hline 1.38346 & & . & & .0 \\
\hline .456499 & & . & 9 & . \\
\hline-.982050 & & .1 & & . \\
\hline-2.20008 & 0 & . & & . \\
\hline-2.38262 & 0 & . & & . \\
\hline-.564078 & & . 0 & & - \\
\hline 1.11102 & & $\cdot$ & & 0. \\
\hline .813817 & & . & $\theta$ & . \\
\hline .434956 & & . & 0 & . \\
\hline .295373 & & + & 0 & - \\
\hline 2.40861 & & , & & . \\
\hline .155453 & & . & 0 & - \\
\hline 1.32720 & & - & & 0 \\
\hline .135070 & & - & 0 & - \\
\hline-.500492 & & . 0 & & - \\
\hline-.588768 & & - 0 & & - \\
\hline-.923777 & & .0 & & . \\
\hline
\end{tabular}


as it is defined here, would decrease. In other words, the sign of the relative price variable should be negative in the regression equation.

The independent influence of the capacity variable should also be negative. As capacity declines, output per unit of energy should also decline, since space heating and other such fixed energy used are spread over a smaller output. But these capacity inefficiencies are likely to be more important in the less energy-intensive industries since the output of energy-intensive industries is more closely correlated with energy use. In other words, the "fixed" energy requirements of a less energy-intensive industry are a greater proportion of the total energy use than is the case in a more energy intensive industry. Thus, when the OER declines as capacity is lowered, it will decline relatively less for energy-weighted output, hence increasing DIFF.

The influence of changes in the ratio of new investment to capital stock is ambiguous--it depends on the type of new investment that is purchased. If the new investment is energy saving, then this new irvestment will increase the efficiency of energy use and retard the shift from more to less energyintensive output. In this case, the sign of the ratio variable would be positive. But if this new investment is labor saving or abates pollution (in the latter part of this period, much of new investment resulted from legislation requiring that pollution abatement measures be undertaken) then the sign of the ratio variable could be negative. The ambiguity associated with new investment relative to capital stock is not resolved by this knowledge. Although intuition suggests that pollution abatement investments might be energy using, this is not always the case. Improvements in efficiencies of automotive power plants and coil coating processes are two examples to the contrary. Pollution abatement requirements in both of these cases led to process efficiencies that have generally been energy saving.

The results of our initial regression, reported in Table 4.1 , bear out our expectations based on economic reasoning. The relative price term (RELPR) enters with the expected negative sign and is highly significant. The capacity variable (CU) also enters with the correct sign, but is not statistically significant at the 5 percent level (although it is at the 10 percent level). The investment ratio (RATIO) is also significant and enters with a positive 
sign, suggesting that some new investment might have been stimulated by increased energy costs. And on the whole, the regression works quite well. The independent variables explain about three-quarters of the total variation in the difference, with only one observation in the period since 1972 outside one standard error--1974: a year of supply shortages, relaxation of price controls and the beginning of a recession. But there is one unsatisfactory aspect of this regression: the Durbin-Watson statistic is low (1.19), suggesting positive serial correlation of the residuals. Since this might be caused by either the lack of a significant variable or serial correlation, alternative specifications are tried.

Table 4.2 reports two further regressions. The first drops the RATIO variable and introduces in its stead TIME, a time trend explained in Section 3. On balance, this contributes negatively--the explained variation declines and now two of the variables are insignificant. Moreover, the signs of both RELPR and CU are now reversed. The second regression in Table 4.2 adds RATIO again, simply altering Table 4.1 by the addition of TIME. But again, there is no net improvement in specification. TIME is not significant, nor is the D-W statistic improved. The explanatory power of the equation, adjusted for degrees of freedom, declines. As with the first regression on this table, the signs of all the other explanatory variables are reversed from those of Table 4.1. Clearly these specifications are less than satisfactory alternatives relative to the first equation.

Much the same thing can be said for the regression reported on Table 4.3. In this case, we try to correct the low D-W statistic by invoking the CochraneOrcutt procedure to correct for serial correlation of residuals. The correction parameter (RHO) suggests that there is significant autocorrelation from year to year; RHO is significant at the 5 percent level. But on closer examination, there is little improvement. The significance of CU declines further, but more important, the $D-W$ still indicates positive serial correlation of residuals. These results are contrary to the findings of Section 3, in that there does not appear to be any obvious method that can be invoked to correct for the problems of serial correlation. This suggests that one or more explanatory variables that should logically be included are missing 
TABLE 4.3. Further DIFF Regression Results-Correction for Serial Correlation

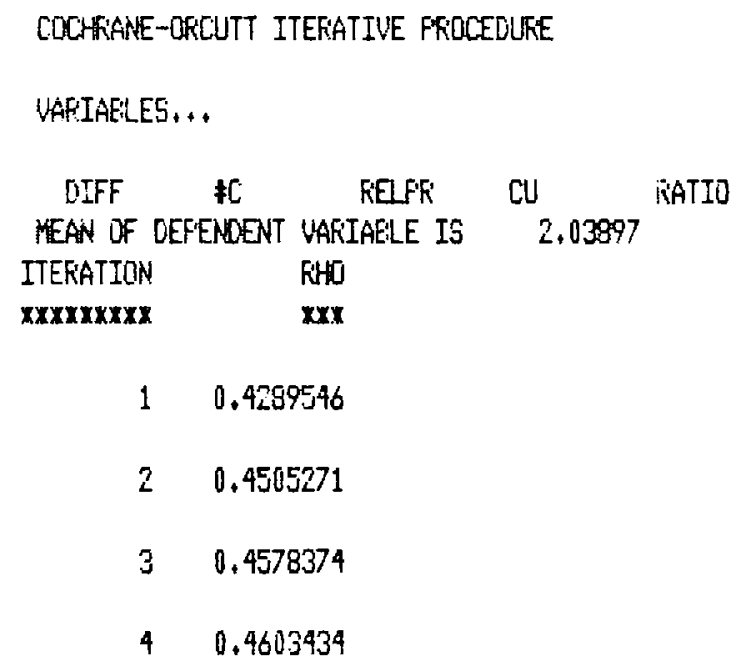

FIIIAL VALUE OF FHHO= NO. OF ITEKATIONS=

0.4603434

4

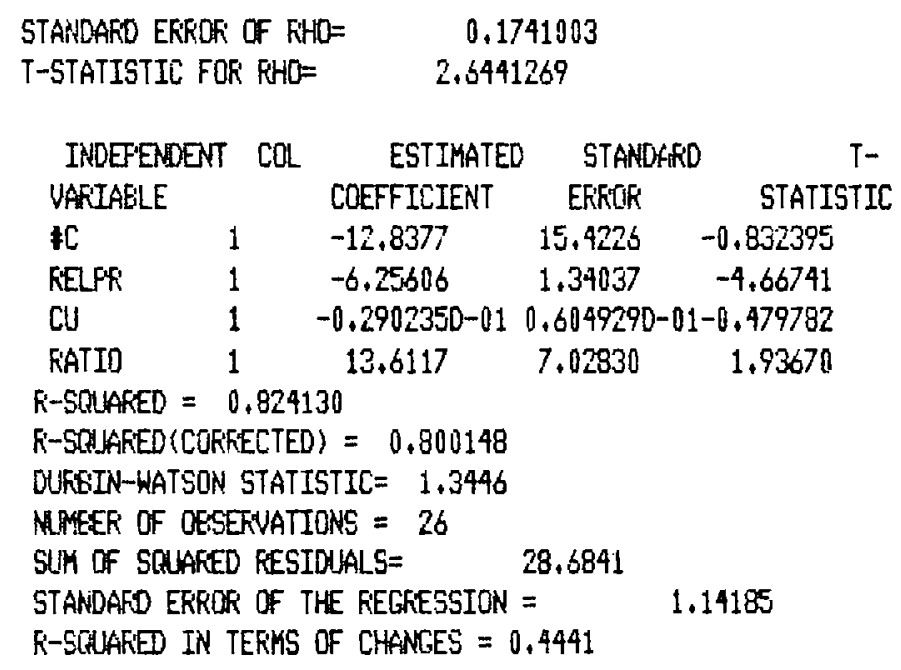


TABLE 4.2. Ordinary Least Squares Regression Results for DIFF-Three Explanatory Variables and TIME

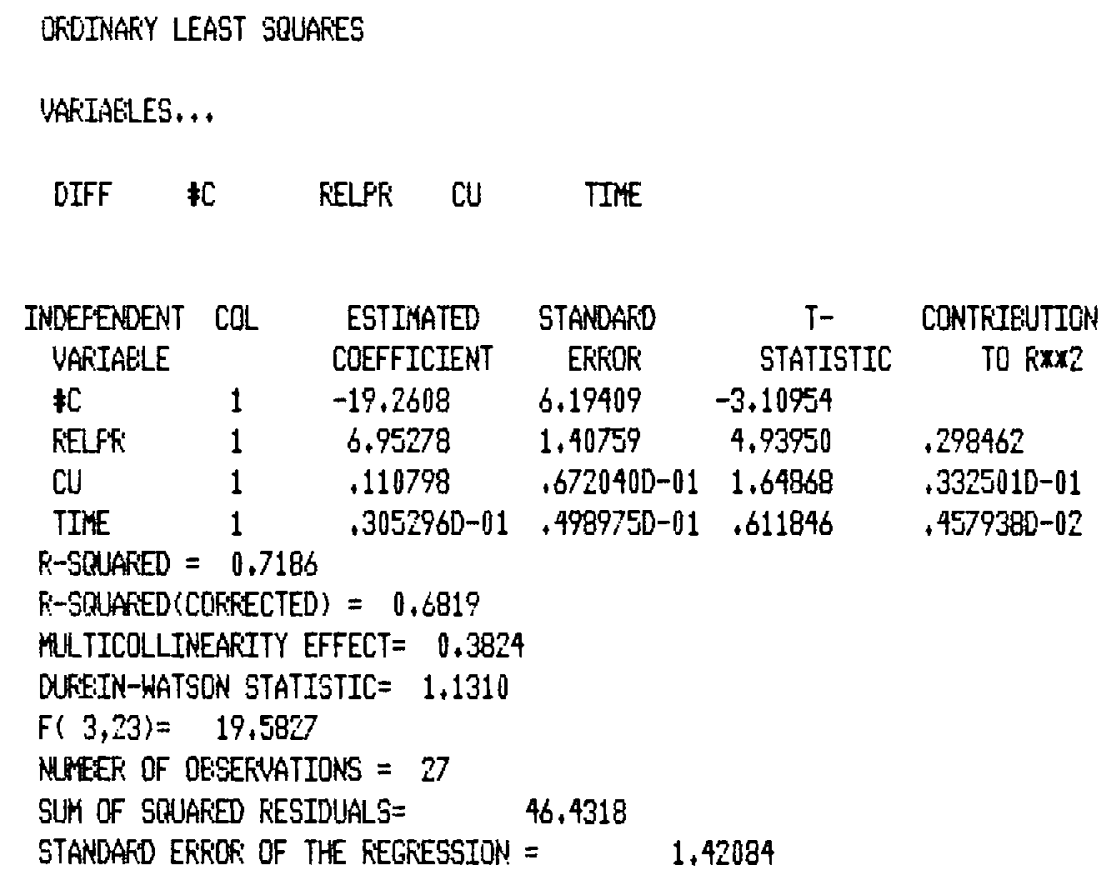


from this regression specification. Rather than speculate on what these might be, at this juncture we simply select the best available specification and continue the analysis of alternative measures.

Table 4.4 is a plot, on a slightly enlarged scale, of the actual and fitted dependent variable from the regression reported in Table 4.1 . The error from this equation is decomposed in the statistics reported below the graph. These statistics indicate that the RELPR, CU, and RATIO serve quite well in explaining the variation that occurs in the difference variable. The Theil inequality coefficient is less than 0.2 , indicating that this equation forecasts better than a naive forecasting model based on previous values of the difference. A decomposition of the error indicates that the bulk of the unexplained error is attributable to differences in covariation, for which there is no statistical correction. There appears to be no discernable bias in the equation, although differences in variance of the two series can account for slightly more than 6 percent of the error. There are two time periods that seem to account for this difference in variance--1954-56 shows quite a wide dispersion of energy and value-added weighted output-energy ratios that is not explained by the independent variables; and 1967-68, because of the normalization procedure, drops to zero. In the post-embargo period, only one year, 1974, shows a large discrepancy from the data, a point mentioned before.

\subsection{ALTERNATIVE SPECIFICATIONS}

A number of alternative measures to the difference between energy weighted and value-added weighted OERs were examined. Among these were percentage differences--the difference relative to the value of either of the OERs--and ratios. These ratios were constructed by dividing one OER by the other; this is comparable to the ratio of, say, energy weighted output to value-added weighted output, since both measures of total enerqy use are the same. Table 4.5 is an example of the results obtained, using the ratio of the energy weighted to the value-added weighted output series as the dependent variable. Since both the output indexes are equal to 100 in 1967, the normalization that applies is $1967=1.0$. In most years, energy weighted output was larger than 
TABLE 4.4. PLOT and Decomposition of Regression Results Shown in Table 4.1

DIFF IS FEFFESENTED EY $*$

FITTED IS REFRESENTED EY $X$

DATE OIFF FITTED -5.10441

5.3776

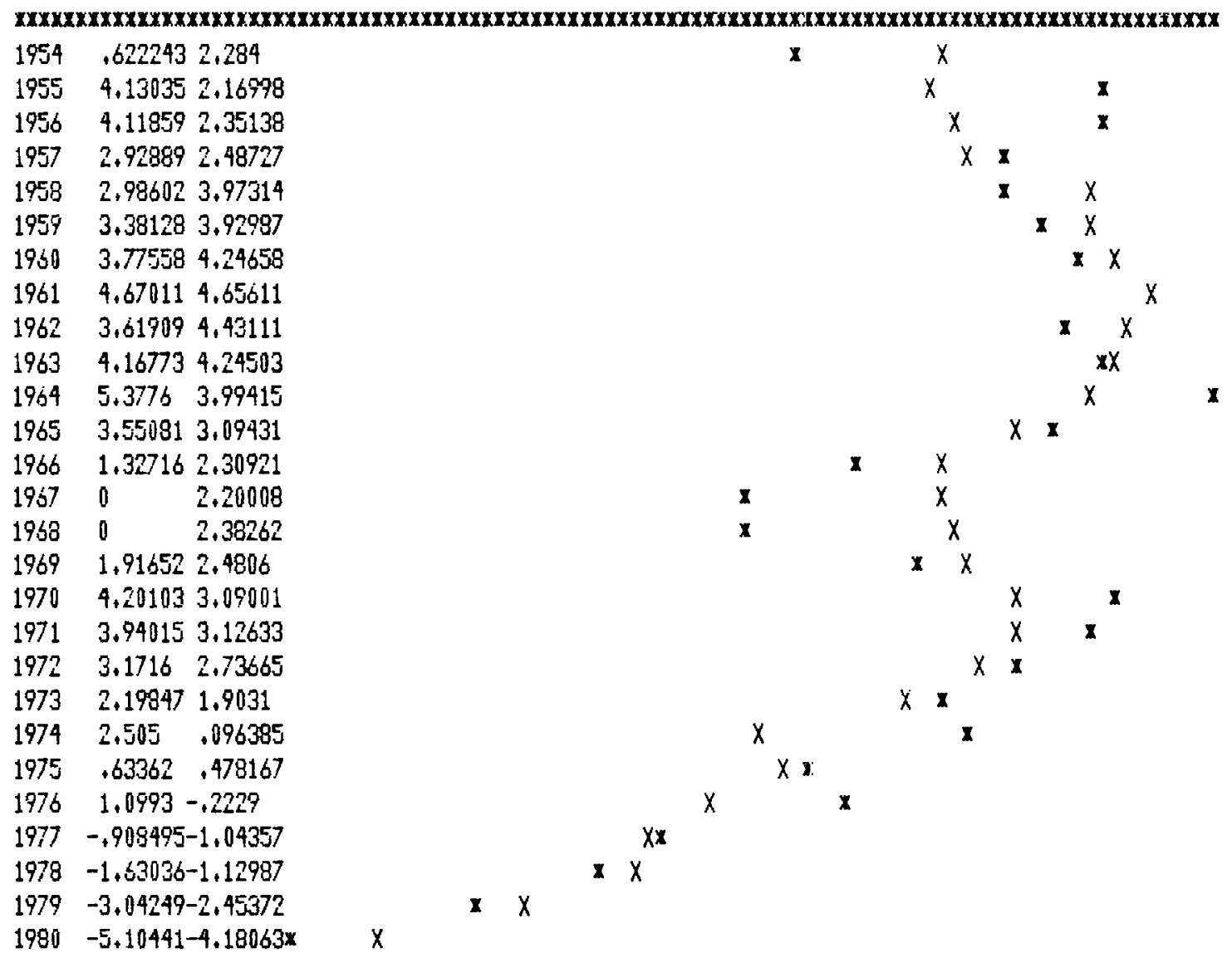

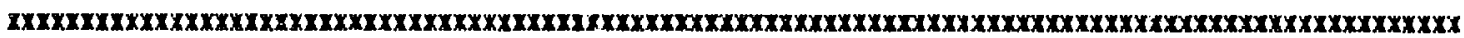

COFFELATION COEFFICIENT $=.98003$

STMAAFED $=.77445$

FOOT-MEAN-SQUAFED EEFFCR $=1.1742$

PEAN AESTLUTE EFFIOR $=.94071$

MEAN EFFOK $=2,2204 E-15$

FEEGFESSIDN COEFFICIENT OF ACTLAL ON FREDICTED $=1$

THEILS INERUAALITY COEFFICIENT $=.19193$

FFACTION OF EFFCK DUE TO EIAS $=3.5763 \mathrm{E}-30$

FFACTION OF EFFOR DUE TO OIFFEFENT UARTATION $=.063814$

FFACTION OF ERFCR DUE TO OIFFEFENT COVAFITATTON = .93619

ALTEFNATIVE OECOAFOSITION (LAST 2 COMFONERTS):

FFACTION OF ERKOR DUE TO DIFFERENCE OF FEGRESSION

COEFFICIENT FFOM UNITY $=1,2875 E-30$

ERFIR DUE TO FESTDUAL VAFIANCE $=1$ 
TABLE 4.5. Regression of RATIOEV Aga inst Three Explanatory Variables

OKODUAYY LEAST SOLAFES

WARIABLES...

RATIOEV HC REPR DU RATDO

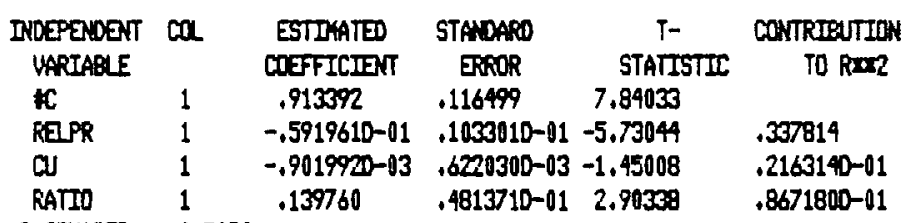

R-SDUAFED $=0.7634$

R-SQUARED(CORRECTED) $=0.7325$

HLTICOLINEARTYY EFFECT $=0.3172$

DUREDH-WATSON STATISTIC $=1.2585$

$F(3,23)=24,735$

MPEER OF OESERMATIONS $=v$

SUM OF SRIARED RESIDUALS= $.3900810-02$

STANDAFO ERROR OF THE REGRESSTON $=\quad .1302310-01$

ACTUAL VAULS PLOTIED NTTH (t) FITTED VALLES PLOTTED FITH (x)
RESTOUALS PLOTTED VITH (0) LTES AT + AND - .1302D-01
ACTUAL WALLES FITED WLLES

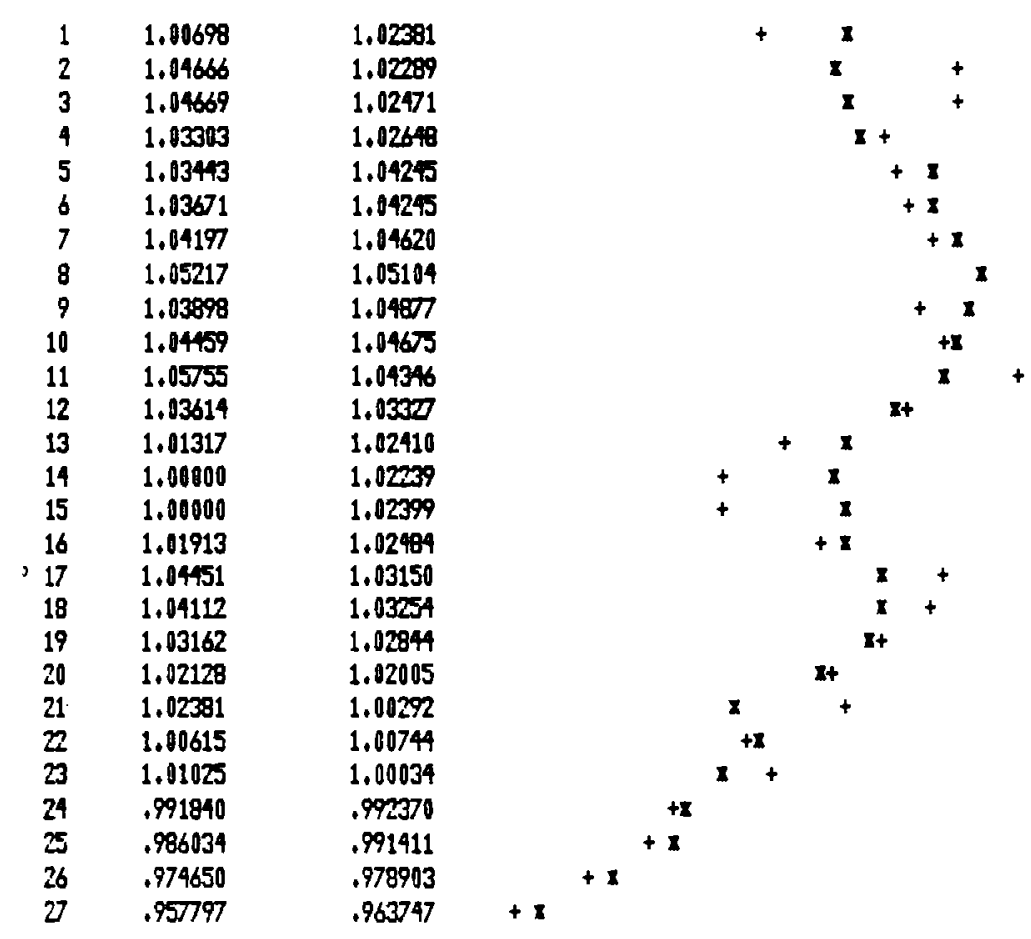

RESIDUALS

$$
\begin{aligned}
& \begin{array}{rrl}
-.1683290-01 & 0 \\
.2376610-01 & : & : \\
.2198030-01 & : & : 0
\end{array} \\
& .6551170-02 \\
& -.8023090-02 \\
& -.5736245-02 \\
& -.4228200-02 \\
& .1133200-02 \\
& -.9790340-02 \\
& -.2163190-02 \\
& .1409310-01 \\
& .2876190-02 \\
& -. .10931 \pi 0-01 \\
& -.2239120-010 \\
& -.2398910-01 \\
& -.514460-02 \\
& .1301200-81 \\
& .8585420-02 \\
& .3180050-02 \\
& .12255200-02 \\
& .2088990-01 \\
& -.1299230-02 \\
& .9916230-02 \\
& -.5303800-03 \\
& -.537 / 140-02 \\
& -.4253390-02 \\
& -.5949830-02
\end{aligned}
$$


value-added output, so the ratio exceeds one. Since 1970 , this ratio has declined, falling below 1.0 in 1977 for the first: time.

The equation reported in Tables 4.5 and 4.6 is only modestly different from the equation reported in Section 4.1. The relative price term is highly significant, as is the ratio of new investment to capital stock. As before, capacity utilization enters with the expected sign, but is not significant at the 5 percent level of confidence. About the same proportion of total variation is explained by the equation and the low D-W statistic remains a problem. The residual plot in Table 4.5 indicates that 1974 is again the only year after the sharp increase in oil prices for which the estimating equation leaves a residual outside the single standard error bounds. Table 4.6 shows the actual and fitted values of the dependent variable on a somewhat larger scale and decomposes the residual error. This decomposition indicates that this version of the difference equation may be somewhat better than the version reported in section 4.2. In this case, the Theil inequality coefficient is nearly zero, indicating considerable improvement over the naive forecast based on past values. Again, there remains about 7 percent of the error attributable to differences in variance, much of which can be explained by the early years of the sample, 1967-68 and 1974 .

Table 4.7 reports two other versions of the difference equation to illustrate that there appears to be little difference between specifications of this equation. The first of these regresses PCTDIF against our cadre of explanatory variables. PCTDIf is constructed by dividing the difference used in section 4.1 by the energy weighted OER. The second regression reported uses the same measure, but normalized to the value-added weighted OER rather than the energy weighted OER. Again, the variables enter the correct signs, RELPR is most significant, and the problem with the D-W statistic remains. For other regressions that were tried but are not reported, the results were similar.

As a result of trying a variety of different specifications, a number of generalizations seem in order. About three-quarters of the variation in the shift from more to less energy-intensive industrial production can be explained by a limited set of economic variables--relative energy prices, capacity utilization and the ratio of new investment to capital stock. With the 
TABLE 4.6. PLOT and Decomposition of Regression Shown in Table 4.5

RATTOEY IS REPFESEMTED EY $x$

FITTED IS REFRESENTED EY $X$

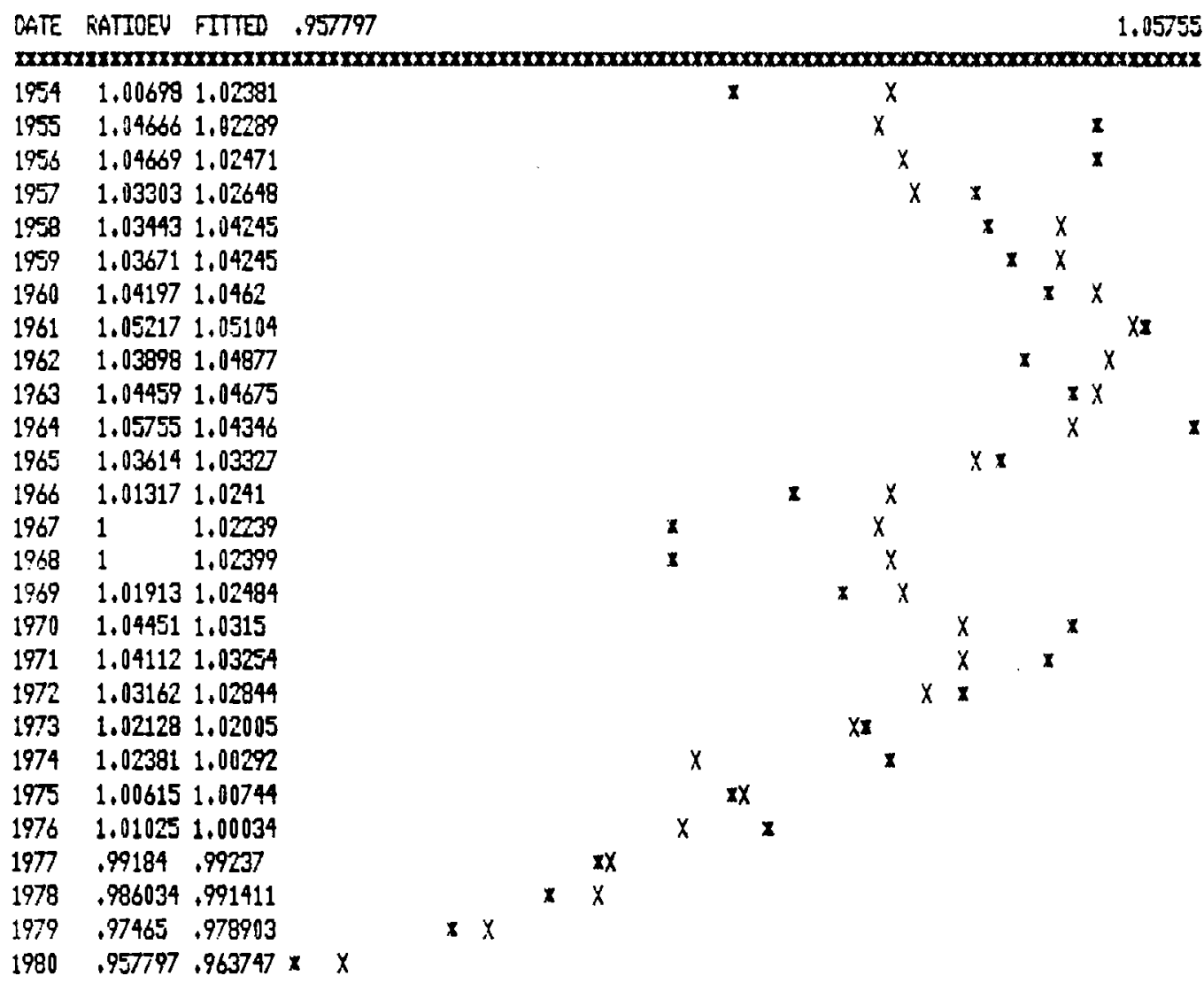

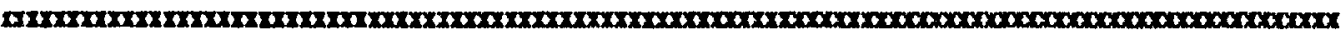

COEFEATION COEFFICIENT $=.87372$

SOUARED $=.76339$

FOOT- FEAN-SRUARED ERROR $=.01202$

YEAN AESOLUTE ERKOR $=.009423$

MEAN EKKLR $=8.2818 E-16$

FECFESSTON COEFFICIENT OF ACTUAL ON PREDICTED $=1$

THETLS INEQUALTTY COERFICTENT $=.0058783$

FRACTION OF ERFOR DUE TO BIAS $=5.4602$ I -27

FFACTION OF EFFCR DUE TO DIFFERENT $V A R I A T I O N=.067394$

FRACTION OF EFKOR DUE TO DIFFEKENT COVARIATION $=\quad .93261$

ALTEFNATIUE OECOMFOSTIION (LAST 2 COMFONENTS):

FRACTION OF EFKOR DUE TO OIFFERENCE OF REGRESGION

COEFFICIENT FROM UNITY $=2,0829 E-32$

EFFOF DUE TO RESTDLLAL VARIANCE $=1$ 
TABLE 4.7. Regressions of Percentage Differences

Against Three Explanatory Variables

OFIINAFY LEAST SOLAFES

WAFIAELES, .,

PLTDIF IC RELFF CU RATIO

\begin{tabular}{|c|c|c|c|c|c|}
\hline $\begin{array}{l}\text { INOEFENOENT } \\
\text { WAFIIAELE }\end{array}$ & $\mathrm{col}$ & $\begin{array}{l}\text { ESTINATED } \\
\text { COEFFICIENT }\end{array}$ & $\begin{array}{l}\text { STANDAFL } \\
\text { EFFITK }\end{array}$ & $\begin{array}{c}\text { T- } \\
\text { STATISTIC }\end{array}$ & $\begin{array}{l}\text { CONTRTBUTION } \\
\text { TO } R \mathbf{x} \times \mathbf{x}_{2}\end{array}$ \\
\hline$+C$ & 1 & $-.7015510-01$ & .112245 & -.625018 & \\
\hline KELFK & 1 & $-.5944100-01$ & $.9952390-02$ & -5.97223 & .356242 \\
\hline $\mathrm{CU}$ & 1 & $-.8902340-03$ & $.5993160-03$ & $-1,48542$ & $.2203780-01$ \\
\hline RATIO & 1 & .129573 & $.4637930-01$ & 2.79602 & $.7808250-01$ \\
\hline \multirow{2}{*}{\multicolumn{6}{|c|}{$\begin{array}{l}\text { R-EOLJAFED }=0.7703 \\
\text { R-SQUAFED (COARECTED) }=0.7403\end{array}$}} \\
\hline & & & & & \\
\hline \multicolumn{6}{|c|}{ MUIICOLLINEAFITY EFFECT $=0.3139$} \\
\hline \multicolumn{6}{|c|}{ DUKETH-WATSON STATISTIC $=1,2386$} \\
\hline \multicolumn{6}{|c|}{$F(3,23)=\quad 25.7072$} \\
\hline \multicolumn{6}{|c|}{ MUREER OF OESEFVATIONS = 27} \\
\hline \multicolumn{3}{|c|}{ SUM OF SWUAFED RESIDLALS= } & $+3621130-02$ & & \\
\hline \multicolumn{3}{|c|}{ STANDAFID ERROR OF THE REGKESSIDN } & & $547500-01$ & \\
\hline
\end{tabular}

OFDINARYY LEAST SQUAFES

VARIAELES...

FCTDIFV IC RELF' CU RATIO

\begin{tabular}{|c|c|c|c|c|c|}
\hline $\begin{array}{c}\text { INDEF'ENDENT } \\
\text { UARIAELE }\end{array}$ & $\mathrm{COL}$ & $\begin{array}{l}\text { ESTIMATED } \\
\text { COEFFICIENT }\end{array}$ & $\begin{array}{c}\text { STANDAFD } \\
\text { EFSLFK }\end{array}$ & $\begin{array}{c}\text { T- } \\
\text { STATISTIC }\end{array}$ & $\begin{array}{l}\text { CONTRTEUTIO } \\
\text { TO } \mathrm{F} \times \mathrm{x}_{2}\end{array}$ \\
\hline$\neq \subset$ & 1 & $-.8660850-01$ & .116499 & -.743426 & \\
\hline FELIF' $K^{\prime}$ & 1 & $10-01$ & $.1033010-01$ & -5.73044 & .337814 \\
\hline CU & 1 & $20-13$ & .62 & -1.45000 & \\
\hline FATITO & 1 & .139760 & $10-01$ & 2.90338 & $.8671800-01$ \\
\hline
\end{tabular}

R-SRUARED $=0.7634$

R-SRUAFED (COKKECTED) $=0.7325$

MLTICOLLINEAFITY EFFECT $=0.3172$

DURETN-HATSON STATISTIC $=1,2585$

$F(3,23)=24.7357$

NLAEER OF OESEENATTONS $=27$

SUM OF SRHAFED RESIOUALS $=\quad .3900810-02$

STANDARO ERROK OF THE REGFESSTON $=\quad .1302310-01$ 


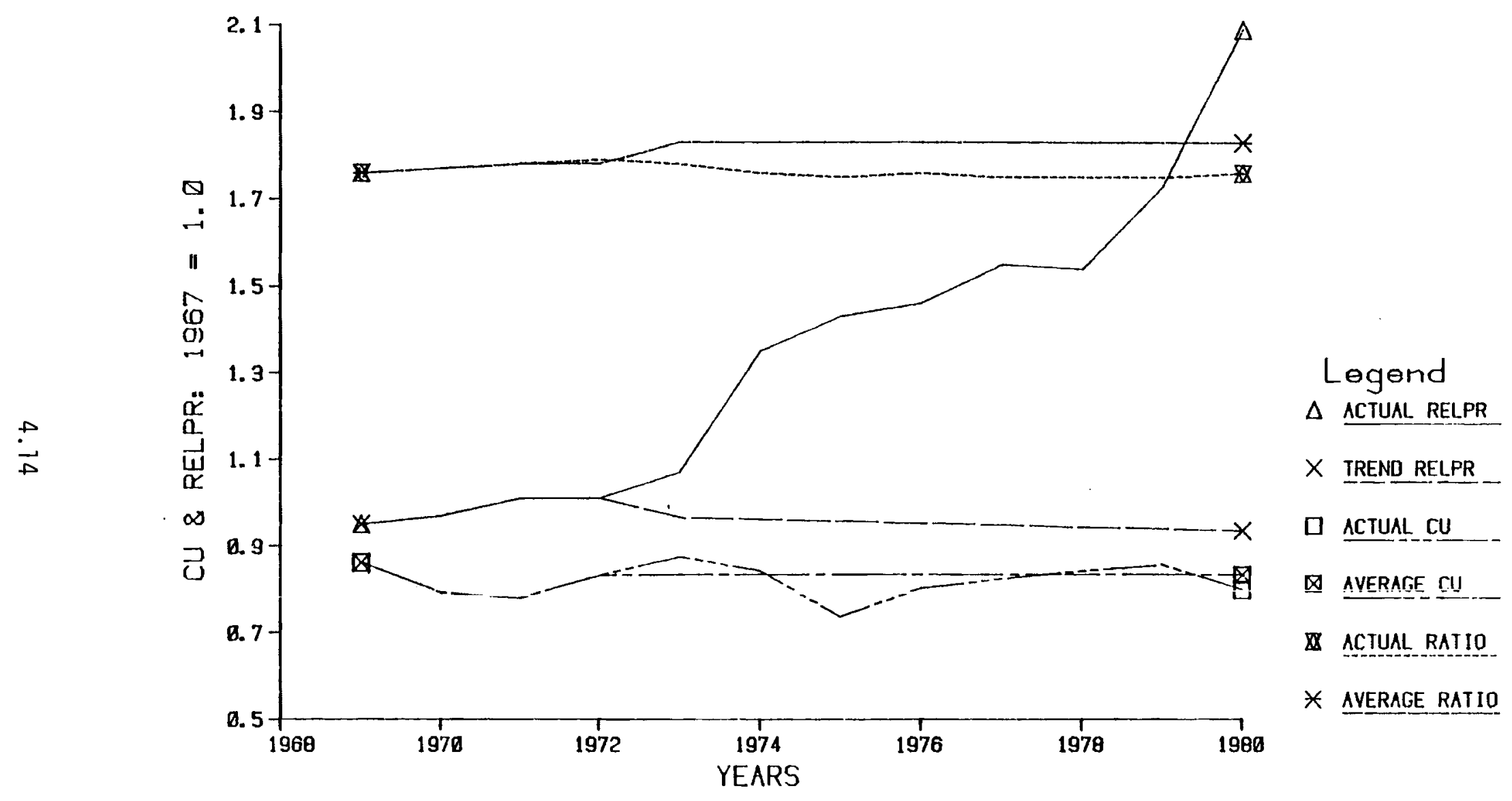

FIGURE 4.1. Actual and Trend Values for Explanatory Variables 
exception of 1974--a perverse year at best--these explanatory variables account for much of the shift since the sharp run-up in energy prices began in the early 1970s. Among these explanatory variables, the ratio of energy to output prices is clearly the most significant factor. The other two economic variables enter the regressions with the correct sign but are not as useful an explanatory variable as is relative price. But there remain a number of disturbing indicators that suggest some of causal variables have been ignored-most prominently, no statistical correction will redeem a low Durbin-Watson statistic, which suggests that some major explanatory factor has been left out.

In the final section of this paper, we will return to the problem presented by these regression results. But for now, we will carry these results one step further, by decomposing the shifts that have occurred into explained and unexplained portions.

\subsection{DECOMPOSITION OF EFFECTS}

To determine the effects that might have occurred without the major shifts that began in the early 1970s, we need to establish a base case. To this purpose we make some assumptions about the trend value of the explanatory variables, then forecast DIFF or RATIOEV based on these trends. To establish trends for RELPR, CU and RATI0, these explanatory variables were regressed against time over the period 1954 to 1972. Of the regressions, only RELPR displayed any time trend--a slight decline of about one-half of one percent per year. For CU and RATIO, since no time trend was evidenced by the data, a simple average over the period 1954-1972 was used. The actual and trend values for these explanatory variables is plotted in Figure 4.1. Trend values (or averages) are shown for the period beginning in 1973, as well as the actual values reported in the appendix and used in the regressions. Notice that the actual value of RATIO is lower during the forecast period than the average for the entire sample period; that CU fluctuates about its sample period average during forecast period; and that RELPR increases every year, except 1978, during the forecast period, whereas a trend value would have seen relative energy prices decline over the forecast period. 
Substituting these base case values into the DIFF equation reported in Section 4.1 provides a base forecast of the difference that might have occurred had the explanatory variables followed trend values. This prediction based on trend is labeled "TREND" and is shown on Figure 4.2. The actual value, labeled "ACTUAL," is the solid line that ends with a triangle. The curve labeled "FORECAST" is a plot of the fitted values from the equation, as shown in Table 4.1. The remaining curve shown on this chart, labeled "ACTUAL RELPR ONLY," gives an indication of the influence of the change in relative energy prices, holding the other explanatory variables at their trend values. The symbols on the right-hand margin of this chart indicate the relative influence of the explanatory variables for the last year in the sample, 1980. Changes in the relative price of energy, represented by the distance from the empty box to the box with the $x$ in it, accounts for about 84 percent of the total change (from the triangle to the upper box). The addition of the other factors, represented by the line ending with an $X$, (CU, RATIO) accounts for about 5 percent, leaving about 11 percent unaccounted for--the distance from the triangle to the $X$.

Figure 4.3 repeats this exercise using the RATIOEV equation rather than the difference equation. There is little substantive difference, although the numbers have changed somewhat. Now changes in relative price alone account for about 85 percent of the total variation, other factors for about 7 percent, leaving about 8 percent unexplained. Figures 4.2 and 4.3 provide convincing evidence that shifts in relative energy prices, of the independent variables used in this analysis, provide the bulk of the explanation of changes in the energy intensity within the industrial sector, accounting for 84 and 85 percent of the total change in 1980 .

But is this really an explanation of cause? Or even an adequate description of change? As a first approximation, changes in relative energy prices appear to account for a substantial portion of the change that has occurred in the energy-intensity measures we have used--the difference between our ratio of energy weighted and value-added weighted OERs. But it is clear that other factors are also important; the statistical evidence clearly indicates that some explanatory factors are missing. So even as a description of change, it is limited. And it is far from an explanation of cause; economic 


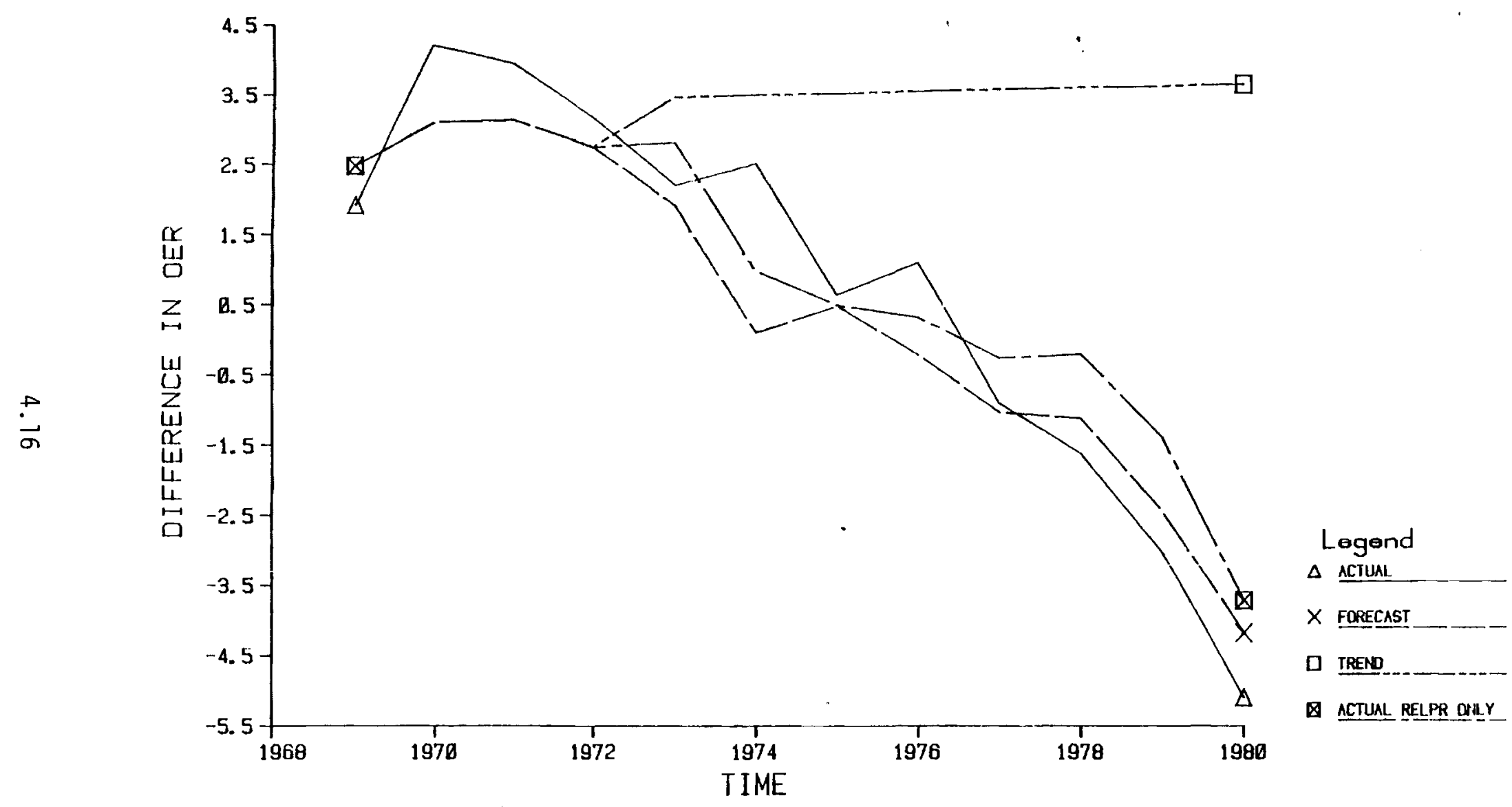

FIGURE 4.2. Actual, Trend and Forecast for Difference in Output-Energy Ratios 


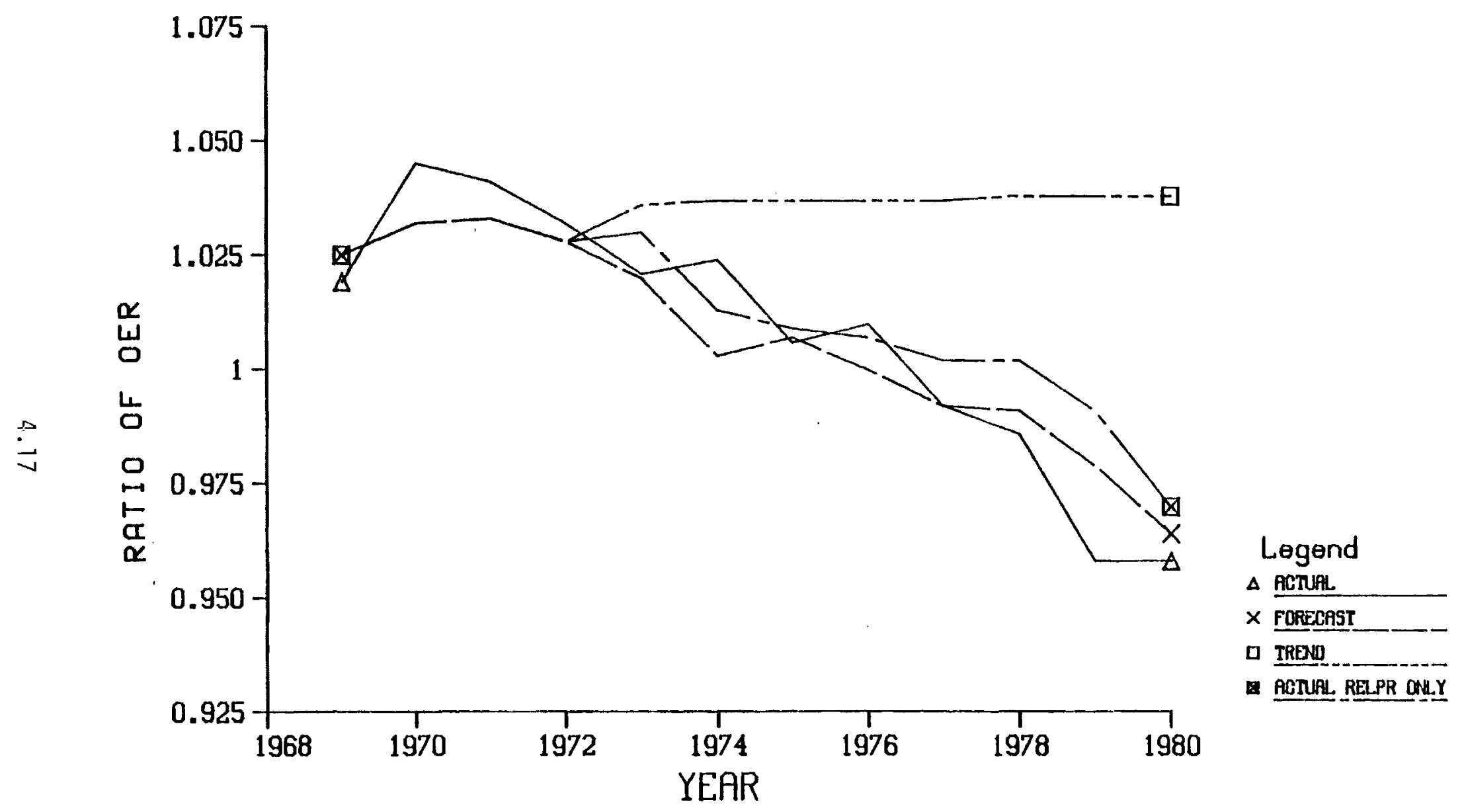

FIGURE 4.3. Actual, Trend and Forecast for Ratio of Industrial Production Indexes 
agents are responsible for and bring about changes in behavior. This analysis brings us no closer to answering which agents are responsible for what shifts that result in these changed measures of energy intensity than we were at the beginning. The limited conclusion that we can draw is this: dramatic shifts in relative energy prices stimulate changes in the behavior of economic agents that lead to a change in the energy productivity of the industrial sector. Whether the responsible agents are individuals altering their consumption behavior, or producers adjusting their factor infuts in response to changing prices, or some other phenomena, this analysis cannot say. In the concluding section, we will return to the question of causes. Now we turn to a monthly analysis of changes in industrial energy productivity. 


\subsection{MONTHLY MEASURES OF ENERGY INTENSITY}

This section estimates the relative importance of economic and seasonal factors that influence energy productivity using monthly data. of interest here are the influence of changing relative prices and cyclical measures of capacity both of which were used in previous sections. Monthly data allows us to examine another possible explanatory variable that affects energy productivity--seasonal factors. The impact of these variables is examined using regression analysis over the period 1973 to 1980. Our focus, again, is on two measures of energy productivity: output-energy ratios (OER) constructed with value-added weights and OER constructed using energyconsumption weights. The difference in these two ratios serves as an indicator of the shifts in energy intensity of industrial output.

The monthly data used in the analysis include total energy consumption, indexes of output constructed from Federal Reserve indexes, capacity utilization indexes published by the Federal Reserve Board, the ratio of energy prices to industrial output prices and seasonal factors. Seasonality of energy use is of special concern; it is handled with the use of an indicator of seasonal energy demand, heating degree days, and dummy variables that capture the annual cycle of energy consumption. Section 5.1 reports the results of a variety of regression specifications designed to discriminate between the relative importance of factors that influence monthly energy use. Section 5.2 summarizes the findings of this section and compares these results to those found in previous sections.

\subsection{ANALYSIS OF MONTHLY DATA}

We begin our analysis by postulating a behavioral relationship between the energy weighted output-energy ratio (OER) and several cyclical and seasonal variables. In the list of explanatory variables we include heating degree days (HDD): as HDD increases, we would expect a decline in the OER as more energy is consumed for space heating that makes little direct contribution to output. Relative prices (RELPR) and capacity utilization (CU) are included for the 
same reasons as they were before. We expect the sign of HDD to be neqative with the sign of the other two variables positive.

The results of the first two reqressions, using a monthly version of OEEMM as the dependent variable and shown on Table 5.1, generally bear out our assumption about the direction of effects. The effect of weather, captured in HDD, enters with a negative sign and is statistically significant at the $1 \%$ level of confidence ( $t$-value greater than 2.63). Fielative price, as expected, enters with a positive sign and is significant at the 5 percent level (greater than 2.0). Capacity utilization also enters with the correct sign and is also significant at the 5 percent level of confidence. But the summary statistics indicate a rather poor fit between the actual and forecast values. The coefficient of determination adjusted for degrees of freedom is only .39, suggesting that the equation leaves more than 50 percent of the variation in the data unexplained. Moreover, the Durbin-Watson statistic is 1.1 , suqgesting strong positive serial correlation in the residuals.

With monthly data, it is quite likely that the effects of the HDD variable are inadequate to capture all the seasonal variation in output. To determine if this is the case, an array of dummy variables is constructed consisting of columns for each of the months. In the January vector, each observation occurring in January is defined as a 1, with all other observations set equal to zero. So in this particular data set, the first column of this dummy array hasa 1 in positions $1,13,27, \ldots$. and 85 . The last column of this dummy array, corresponding to the month of December, has a 1 in locations 12, 24, . -., and 96, with zeros in all other locations. We then introduce this array into the regression in place of the constant term. Using this array is equivalent to allowing a separate regression intercept for each of the 12 months. With an intercept of 75.8 for the first regression, we would expect the seasonal intercepts to be about the same magnitude, with some variation over the year. In the colder months which require greater use of eneray for space heating, we would expect this intercept to be lower than in the spring and fall months. The second panel in Table 5.1 shows the output of this regression. 
TABLE 5.1. Regression of Monthly OEEMM Against Three Explanatory Variables and Monthly Dummy Variables

DFDLWAYY LEAST SQUAFES

WARTAELES...

OEEM HC RELFR CI HDD

\begin{tabular}{|c|c|c|c|c|c|}
\hline INDEFEIOENT & COL & ESTIMATED & STAK:DAFID & $T-$ & CONTREELTIO \\
\hline JAFIAELE & & COEFICIENT & EKKCR & STATISTIC & TO $\mathrm{kxx} 2$ \\
\hline$\neq$ & 1 & 75.8151 & 14.8251 & 5.11399 & \\
\hline RELFR & 1 & 6.54789 & 2.76914 & 2.36459 & $.3734790-01$ \\
\hline $\mathrm{Cu}$ & 1 & , 3585338 & .159384 & 2.24953 & $.3380140-0$ \\
\hline 100 & 1 & $-.1432950-01$ & $.2094220-0$ & -6.84237 & .31277 \\
\hline
\end{tabular}

R-SQUAFED $=0,3855$

R-SRUAFED (COFFECTED) $=0.3654$

BHLTCOULINEAFITY EFFECT $=0.0016$

DUKBTN-WATSON STATISTIC $=1,1452$

$F(3,92)=19.2363$

NUMEEF OF DESERVATICNS $=96$

SLH OF SQUARED RESIOUALS=

4708.40

STANDAFD ERKOF OF THE FEGRESSTON =

$7+15390$

VAFITABLES...

\begin{tabular}{|c|c|c|c|c|c|}
\hline OEFA & DUitiY & RELPR & HDD & & \\
\hline $\begin{array}{l}\text { DNDEFENDENT } \\
\text { VARTAEAE }\end{array}$ & COL & $\begin{array}{l}\text { ESTITATED } \\
\text { COEFFICIENT }\end{array}$ & $\begin{array}{l}\text { STANDAFD } \\
\text { ERKOR }\end{array}$ & $\begin{array}{c}\text { T- } \\
\text { STATISTIC }\end{array}$ & $\begin{array}{l}\text { CONTRIPUTION } \\
\text { TO F } \mathbf{x} 2\end{array}$ \\
\hline DUAY & 1 & 61.2186 & 10.3100 & 5.93778 & $.4880430-03$ \\
\hline DURAY & 2 & 77.2355 & 9.69216 & 7.96886 & $.8790200-03$ \\
\hline DUPFY & 3 & 72.0424 & 9.09125 & 7.92436 & $.8692380-03$ \\
\hline DURAY & 4 & 77.7929 & 8.55897 & 9.08905 & $.114353 \mathrm{D}-02$ \\
\hline DUAY & 5 & 69.6768 & 8.39997 & 9.29489 & $.9524250-93$ \\
\hline DLRTY & 6 & 72.5393 & 8.40920 & 8.62617 & $.10300-02-02$ \\
\hline DUWHY & 7 & 64.0975 & 8.44732 & 7.58791 & $.796992 \mathrm{D}-03$ \\
\hline DUAYY & 8 & 65.4230 & 8.46559 & 7.72811 & $.8267160-03$ \\
\hline OUIFY & 9 & 69.2117 & 8.47640 & 8.16523 & $.9228820-103$ \\
\hline OUMAY & 10 & 62.0071 & 8.58410 & 7.27348 & $.7202760-03$ \\
\hline Ourary & 11 & 62.3975 & 8.99692 & 6.93432 & $.6656060-03$ \\
\hline DUAYY & 12 & 58.8369 & 9.83448 & 5.98271 & $.4954500-03$ \\
\hline RELPR & 1 & 8.51977 & 1.58917 & 5.35113 & $.39785000-03$ \\
\hline U & 1 & .407184 & $.8940810-01$ & 4.55427 & $.2371040-03$ \\
\hline HDD & 1 & $-.114964[-11$ & $.6602430-02$ & -1.74124 & $.4196880-144$ \\
\hline \multicolumn{6}{|c|}{ Ri-SQUAAED $=0.8306$} \\
\hline \multicolumn{6}{|c|}{$\begin{array}{l}R \text {-SELAFED(COHFUTED AEOUT ZERO) }=0 \text {. } \\
\text { R-GALAFED (COFFECTED) }=0.9997\end{array}$} \\
\hline \multicolumn{6}{|c|}{ MLLTCOLLTNEAKTTY EFFECT $=0.9984$} \\
\hline \multicolumn{6}{|c|}{ DLFEDN-WATSON STATISTIC $=0.9025$} \\
\hline \multicolumn{6}{|c|}{$F(15,92)=26.7954$} \\
\hline \multicolumn{6}{|c|}{ NUNEER OF OESEFUATIONS = 96 } \\
\hline \multicolumn{6}{|c|}{ SLIM OF SDIAFFD RESTOLALS= } \\
\hline STABDAFO EF & FROR O & THE REGRESSTI & & 50 & \\
\hline
\end{tabular}


This regression is an indication of how important the seasonal component is in explaining the movement of a monthly output-energy ratio. The months where the intercepts are highest are April, February (probably because of the shorter length of the month), May, June, and September; the intercept is lowest for the months of December, January, October and November. All of the monthly dumy variables are significant at the $1 \%$ level. The difference between the largest and smallest is 18.9, which is more than two times the average standard deviation of about 8.9. The seasonal variation in the OER data appears to be adequately captured by this seasonal dumy variable. Note that the statistical significance of the relative price and capacity utilization variables increases as do the magnitude of these coefficients. But with the introduction of the seasonal dummies, HDD no longer enters significantly as before (although it does enter at the $10 \%$ level of confidence--a t-value greater than 1.67 ), and it has the correct sign. Yet this regression still has one major flaw -- the Durbin-Watson (D-W) statistic is 0.90 , again indicative of strong positive serial correlation.

The regression reported on Table 5.2 re-estimates the dumy variable equation using the method of Cochrane and 0rcutt to compensate for serial correlation. The parameter estimate for first order serial correlation is .586 and is significant at the $1 \%$ level of confidence. This adjustment does not alter, in any major way, the findings of the previous regression, but there are some slight difference. Although all the dummy coefficients are significant, the difference between the maximum and minimum values is now larger and the largest and smallest months have changed (February and July, respectively). The standard errors of all the variables have increased somewhat, but have little substantitive effect on our conclusions. With this correction, HDD is definitely a contributing factor to the regression, entering with the highest $t$ value. Stated differently, HDD now has a substantial independent explanatory effect on OER when seasonal and cyclical factors are adequately defined.

The OER (OEEMM) using the energy weighted index of output for manufacturing and mining is used to establish the structural form of the regression equation that seems adequate to explain the variation in the data. An alternative definition of the OER is next analyzed to see if these results carry over to different definitions of the dependent variabie. Our second and 
TABLE 5.2. Monthly Regression of OEEMM Correcting for Serial Correlation

COCHFANE-DFCUTT ITERATIVE FROCEDURE

VAFIAELES . .

\begin{tabular}{|c|c|c|c|}
\hline OEEMM & DUWYY & FELPF & \multirow{4}{*}{$\begin{array}{l}C U \\
\quad 109.320\end{array}$} \\
\hline KEAN OF OE & ENDENT & VARIAELLE IS & \\
\hline ITERATION & & FHO & \\
\hline $\operatorname{xxxxx\times x\times x}$ & & $\mathbf{x x x}$ & \\
\hline 1 & 0.584 & 2377 & \\
\hline 2 & 0.585 & 9473 & \\
\hline
\end{tabular}

FINAL VALUE OF FHHO $=0.5859473$

AT. OF ITEFATIONS $=2$

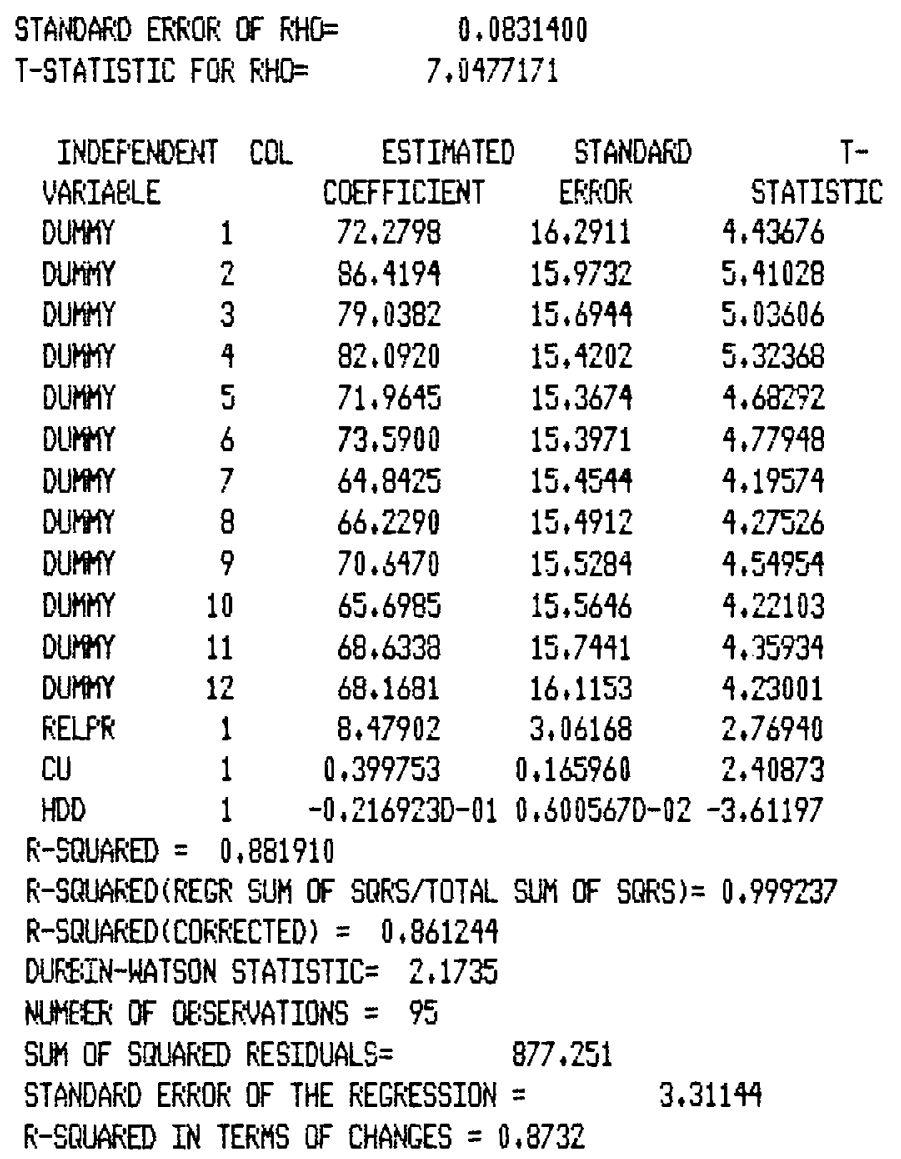


final dependent variable is OEVMM: the OER constructed using the value-added weighted index of production for manufacturing and mining only.

Table 5.3 shows the same two regressions reported in Table 5.1 ; first the regession of OEVMM against RELPR CU, and $H D D$, then the same regression with the seasonal intercepts. The first equation in Table 5.3 has much the same problems as its counterpart in Table 5.1. The D-indicates that positive serial correlation of residuals exists and less tnan half of the total variation is explained by the independent variables. The intercept is lower in this equation, but the coefficients for RELPR and CU are higher, and somewhat more significant. In the second regression, the level of significance of the seasonal durmies is somewhat lower, and the magnitude of the two "economic" explanatory variables is somewhat higher (but consistent with somewhat lower seasonal factors). Unlike the second equation in Table 5.1 , HDD is no longer a significantly explanatory variable. So we conclude that on a monthly basis there is little difference between the energy weighted and value-added weighted OERs for manufacturing and mining. Adjusting the second regression of Table 5.3 for serial correlation (shown in Table 5.4) has much the same effect for OEVMM as it has for OEEMM. All the explanatory variables, including HDD, are highly significant and the $D-W$ improves to about 2.2. We note that approximately the same change occurs with the seasonal dummies.

But clearly there is a significant difference between weighting production indexes using value-added and energy-use weights. Energy price increases can bring about changes in industrial composition through substitution in the production process or through shifts from greater to lesser energy-intensive sectors. The latter could readily occur with consumption shifts resulting from changing relative prices that reflect the full cost of production. The regression results shown on Tables 5.5 and 5.6 try to measure the influence of economic and seasonal variables on this shift, as measured by the difference between the energy-use and value-added OERs.

The first regression reported in Table 5.5 has a number of significant problems, some of which we have seen before. Although the RELPR and CU variables enter the regression significantly, HDD does not. Somewhat surprisingly, the equation accounts for about 60 percent of the total variation 
TABLE 5.3. Monthly Regression of OEVMM Against Three Explanatory Variables and Monthiy Dummy Variables

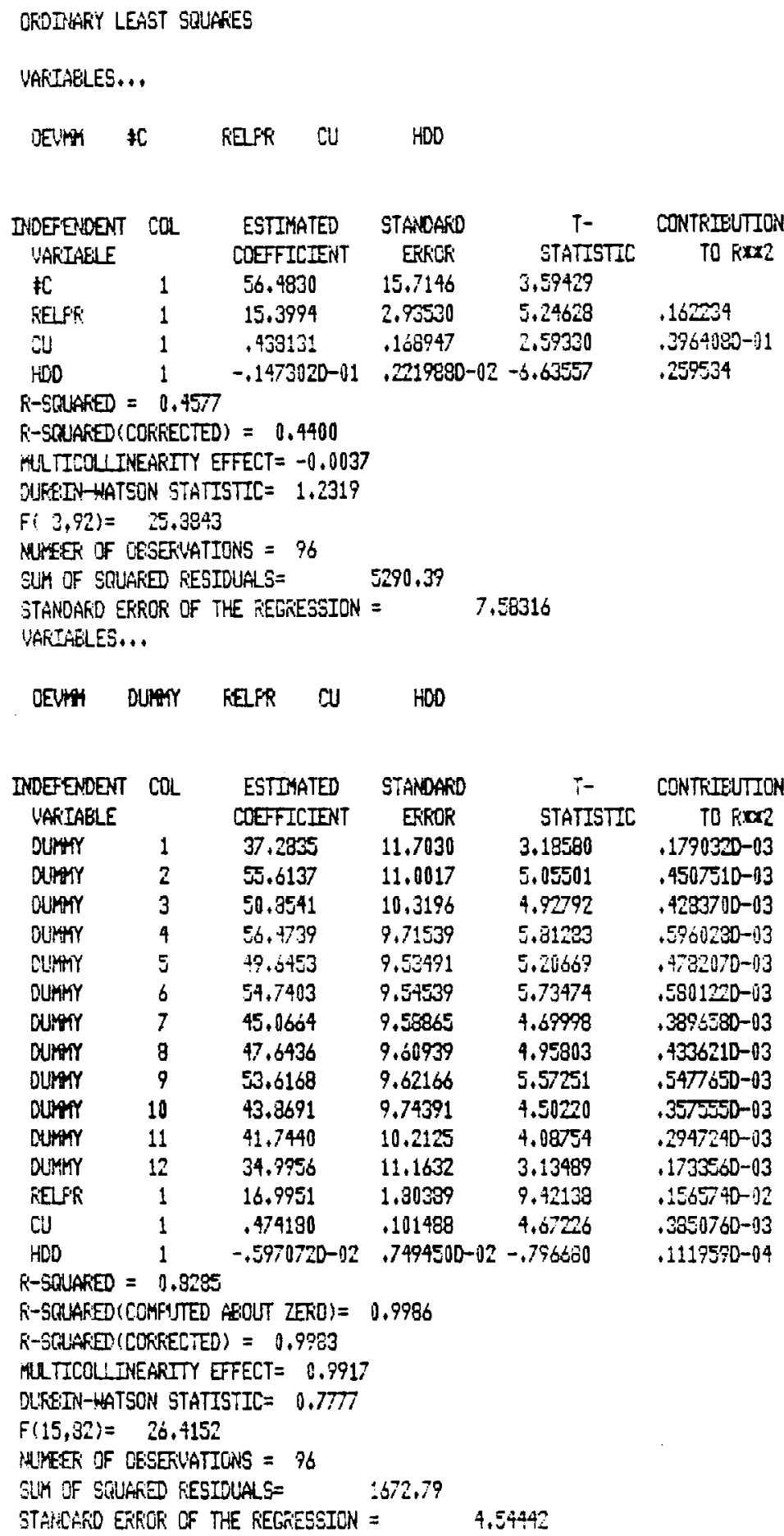


TABLE 5.4. Monthly Regression of OEVMM Correcting for Serial Correlation

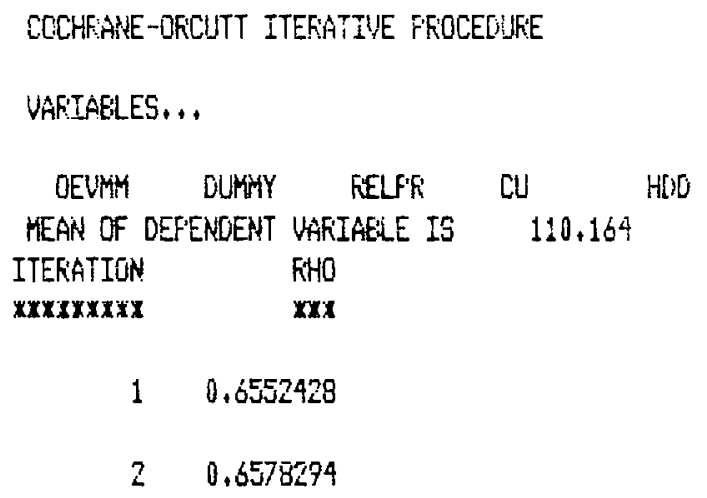

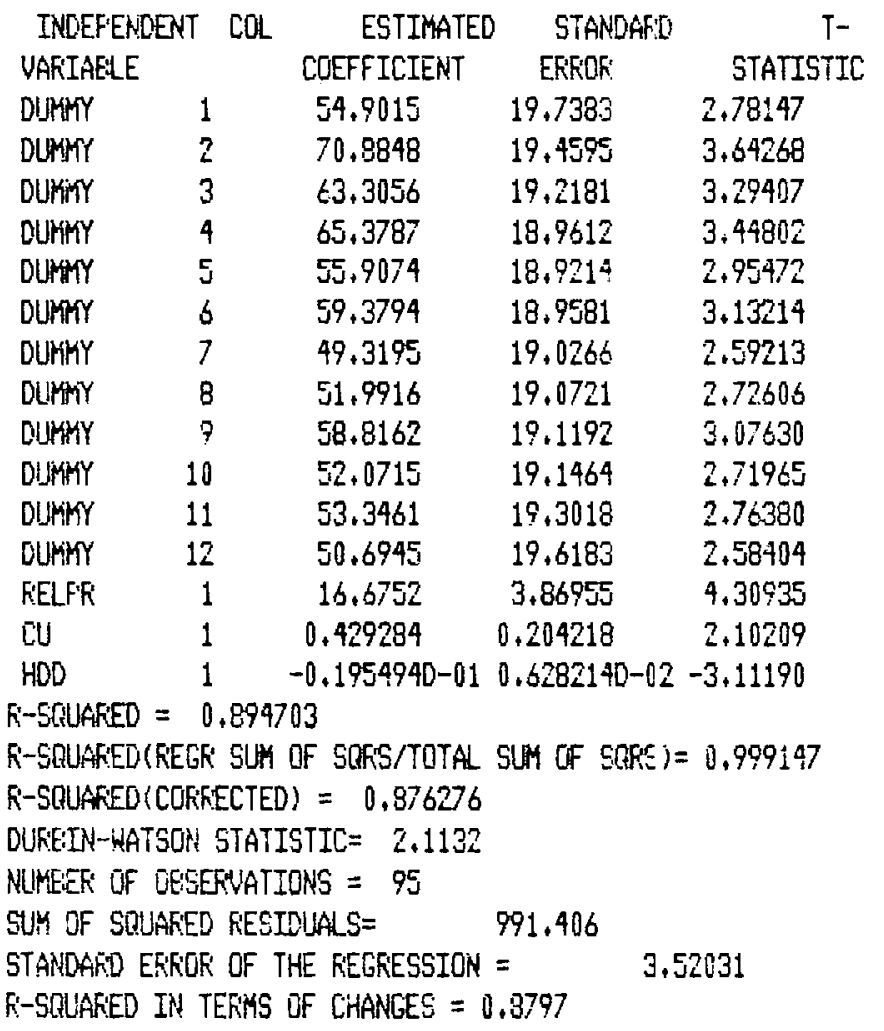


TABLE 5.5. Month1y Regression of DIFF Against Three Explanatory Variables and Monthly Dummy Variables

OFOIHAFYY LEAST SQUAFES

UAFITELES. . .

OIFF $\$ C$ FEEFR CU HDO

\begin{tabular}{|c|c|c|c|c|c|}
\hline $\begin{array}{l}\text { INDEFENDENT } \\
\text { UARIAELE }\end{array}$ & $\mathrm{COL}$ & $\begin{array}{l}\text { ESTIMATED } \\
\text { COEFFICIENT }\end{array}$ & $\begin{array}{l}\text { STAHEAFD } \\
\text { EHSOR }\end{array}$ & $\begin{array}{c}\text { T- } \\
\text { STATISTIC }\end{array}$ & $\begin{array}{c}\text { CONTRIELTION } \\
\text { I9 F } \mathbf{x} \times \mathbf{2} \text { ? }\end{array}$ \\
\hline$\neq c$ & 1 & 17.3321 & 4.63025 & $4.7967 \delta$ & \\
\hline FELLFY & 1 & -8.85151 & .752500 & -11.7531 & .591005 \\
\hline$W$ & 1 & $-.7959240-01$ & $.4332900-91$ & -1.33693 & $.144 .2450-11$ \\
\hline$H D O$ & 1 & $.4007350-03$ & $.5693210-13$ & .703886 & $.2117790-02$ \\
\hline
\end{tabular}

Fi-STLAKED $=0.5067$

R-SRLAFED(COKKECTED) $=0.5939$

HULTLOLLINEARITY EFFECT $=-0.0008$

OUKEIN-HATSON STATISTIC $=0.7227$

$F(3,72)=47.3096$

NUMER OF CESENVATONS = 96

SUHY OF SALUARED KESTULLLS= 347.971

STANDAFO EFROR OF THE REGRESEION = 1.94481

UAFTAELES. . .

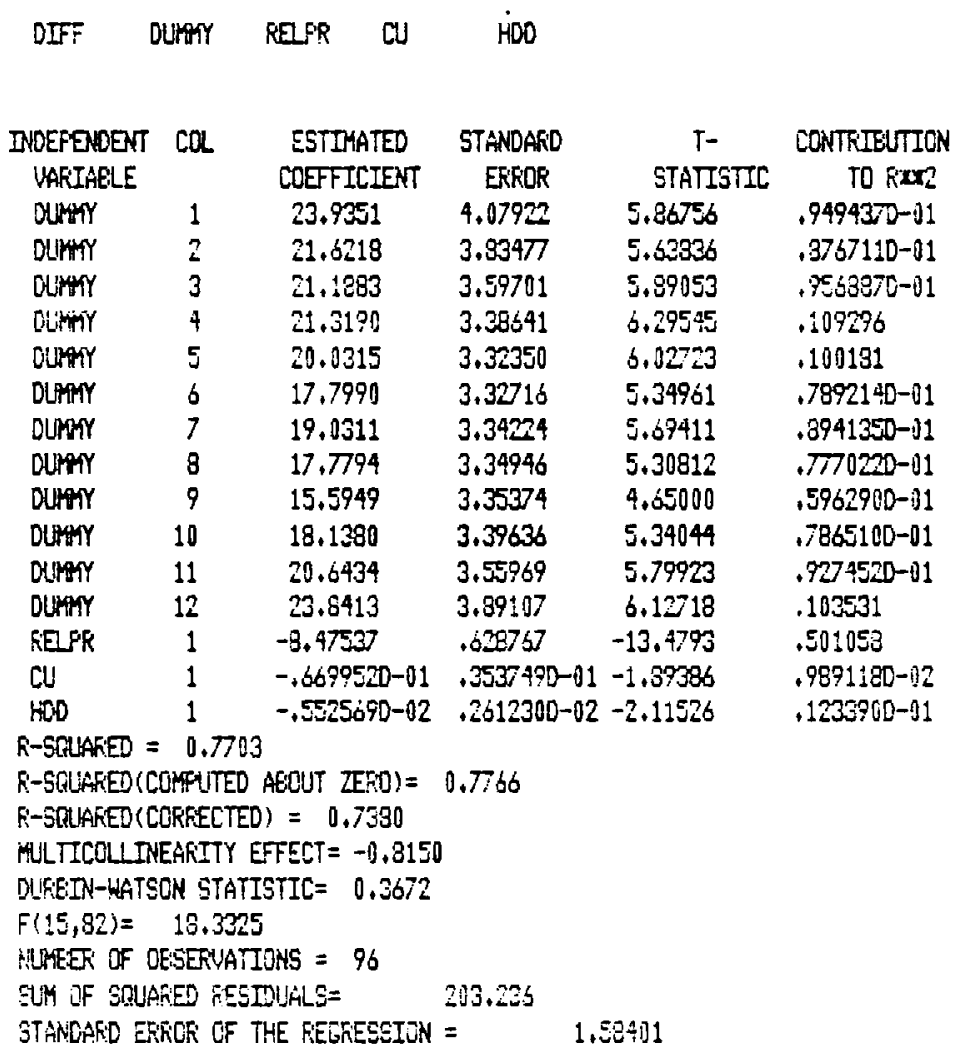


TABLE 5.6. Monthly Regression of DIFF Correcting for Serial Correlation

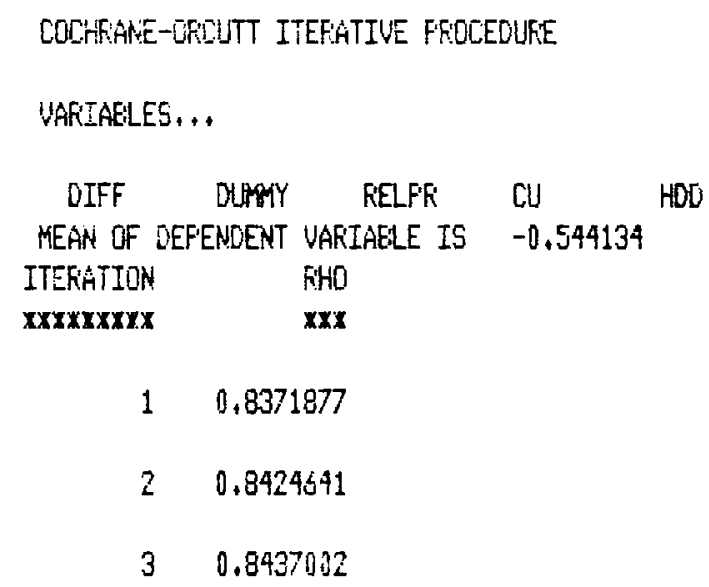

FINAL VALLLE OF FHOL= $\quad 0.8437002$ NO. OF ITERATIJNS= 3

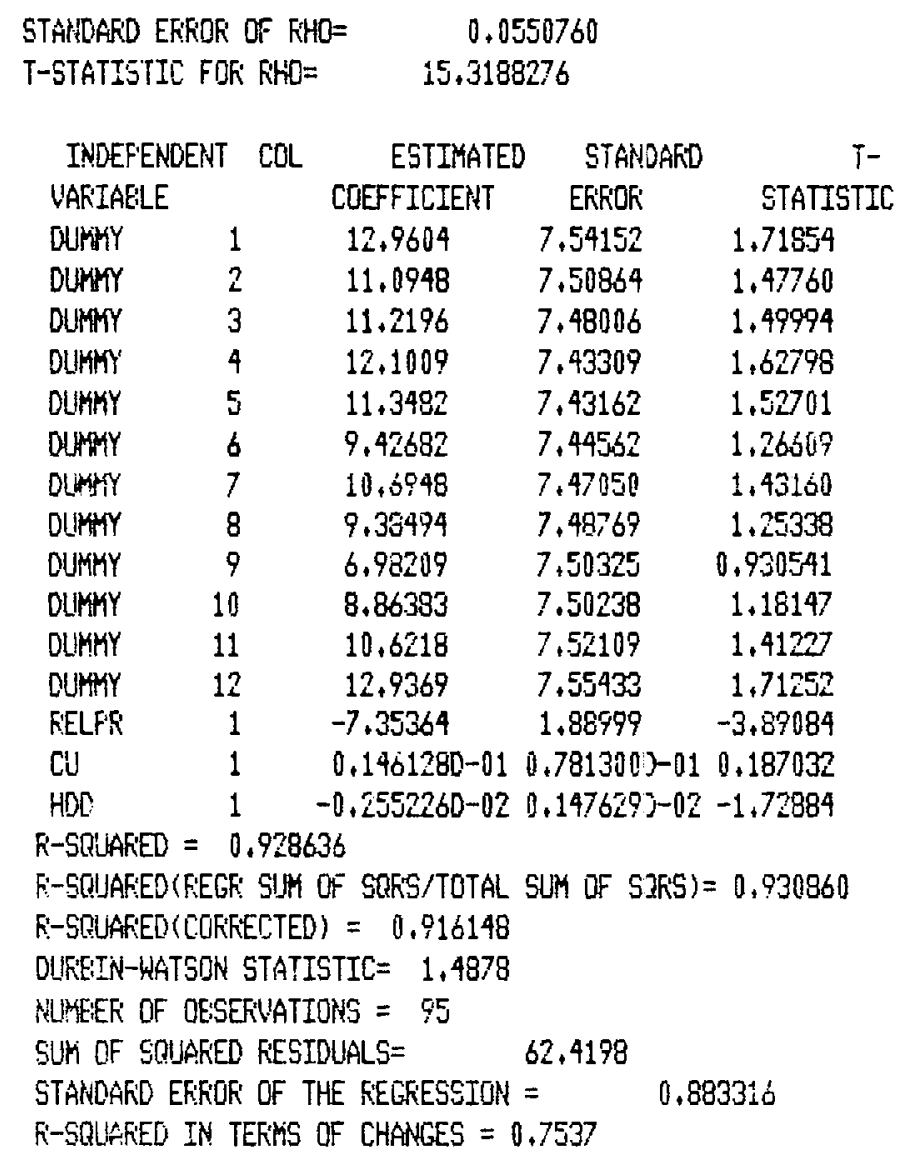


of the dependent variable. And the $D-W$ statistic, at 0.72 , signals strong positive serial correlation of the residuals. Reintroducing the intercept dumies improves the fit of the equation, but does little to improve the indicator of serial correlation. Again we note that this seasonal artifact raises the explanatory power of the equation to the level shown in the annual regressions--about three-fourths of the total variation is explained. The relative price and capacity variables again enter with the correct sign. RELPR is highly significant, but $C U$ is only marginally so. Note that the size of the HDD variables improves in significance, but changes sign.

Table 5.6 repeats the second equation of Table 5.5 using the Cochrane0rcutt procedure to correct for serial correlation. This procedure improves the fit dramatically, raising the explained variation to 92 percent, but has a number of surprises. The statistical significance of the dumy intercepts, CU and HDD are all adversely affected, with CU now clearly insignificant. And again, the $D-W$ statistic, at 1.5 , is much below its expected value of 2.0 . As in previous sections, we conclude that this points to the exclusion of important explanatory variables that should be included.

\subsection{SUMMARY}

The main difference between an examination of annual time series and monthly data is the importance of seasonal factors in explaining month-to-month changes in both energy productivity and energy intensity in the industrial sector. Relative price remains the most significant explanatory variable of energy intensity, but monthly data highlight the important role that seasonal variables play in energy productivity measures. Cyclical variables are also important in explaining monthly energy productivity. Using annual data, CU is of marginal value as an explanatory variables; it is much more important in the monthly OER equations, but is less significant in explaining monthly differences in OERs. An important finding of both the monthly and annual analysis is that important explanatory variables are not included in this particular set of independent variables. We have suggested in the introduction what some of these variables might be. This analysis suggests, above all other conclusions, that further work is required to sort out the causes of changing energy intensity of the industrial sector. 


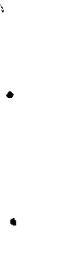




\section{REFERENCES}

Anderson, Richard G. 1980. "The Treatment of Intermediate Materials in the Estimation of the Demand for Eneray: The Case of U.S. Manufacturing, 19471971." The Energy Journal. I(4): 75-94.

Belzer, D. B. and J. M. Roop. 1981. "Technoloqical Change, Prices and the Demand for Energy in U.S. Manufacturing." Symposium on Technological Change and Productivity, Washington D.C., December 2.

Berndt, Ernst R. and David 0. Wood. 1981. "Engineering and Econometric Interpretations of Energy-Capital Complementary: Reply and Further Remarks." American Economic Review. 75(5): 1105-1110.

Bohi, Douglas R. 1981. Analyzing Demand Behavior: A Study of Enerqv Elasticities. The Johns Hopk ins Press for Resources for the Future, Inc., Baltimore.

Darby, Michael R. 1982. "The Price of $0 i 1$ and World Inflation and Recession." American Economic Review, 72(4):738-751.

Hirst, Eric, et a1. 1981. "Energy Use for 1973 to 1980: The Role of Improved Energy Efficiency." ORNL/CON-79, Oak Ridge National Laboratory, Dak Ridge, Tennessee.

Hudson, E. A. and D. W. Jorgenson. 1974. "U.S. Energy Policy and Economic Growth, 1975-2000." The Bell Journal of Economics and Management Science. 5: 461-514.

Kristensen, Chris and Joseph Correia. 1980. "Energy Usage Trends for Selected Manufacturing Industries." Industrial Economic Review. (Sumer):20-31.

Magnus, Jan R. 1979. "Substitution Between Energy and Non-Eneray Imputs in the Nether lands, 1950-1976." International Economic Review. 20(2):465-484.

Marlay, Robert C. 1981a. "Effects on Investment in Energy Conservation of DOE's Programs and of Market Forces." Working Paper, Office of Energy Markets Policy, Department of Enerqy, Washington, DC 20545.

Marlay, Robert r.. 1981b. "Industrial Energy Productivity, 1954-1980: Abstract and Summary." Office of Energy Markets Policy, Department of Energy, Washington, DC 20545.

Marlay, Robert C. 1982. "The What and Why of Recent Changes in U.S. Energy Consumption: The Industrial Sector." Draft, Office of Energy Markets Policy, Department of Energy, Washington, DC 20545.

Mork, Knut Anton and Robert E. Ha11. 1980a. "Energy Prices and the U.S. Economy in 1979-1981." The Energy Journal. I(2):41-53. 
Mork, Knut Anton and Robert E. Ha 11. 1980b. "Eneray Prices, Inflation, and Recession, 1974- 1975." The Enerqy Journal. I(3):31-63. 


\section{APPENDIX}

DATA DESCRIPTION 


\section{APPENDIX: Data Description}

Table A.l tabulates the data used in the annual analysis of energy productivity. The variable labels are as follows: OEEMM is the energy weighted output index divided by energy consumption and normalized to $1967=$ 100, for manufacturing and mining. OEVMM is the value-added weighted output index per unit of energy consumption, normalized so that $1967=100$. Similarly, OEEI and OEVI are the energy and value-added output-energy ratios, respectively, for the industrial sector. RELPR is the producer price index (PPI) for fuels and power relative to the PPI for all industrial comodities; RELPR measures the price of energy relative to other industrial prices. RATIO is the proportion of producers' new durable equipment relative to the total stock of durable equipment, adjusted so that the order of magnitude is the same as that of RELPR. RATIO is an indicator of the newness and thus, we presume, the energy efficiency of capital. CU is an index of manufacturing capacity utilization. TIME and TSQ are measures of time centered about 1967.

The output per unit of energy measures were provided by R.C. Marlay (Department of Energy) and are as yet unpublished. The industrial production indexes published by the Federal Reserve Board of Governors (FRB) -approximately 135 of which are published in detail--are used to create indexes that are benchmarked to census indexes of output at the 4-digit Standard Industrial Classification (SIC) level. These revised industrial production indexes are then aggregated using either value-added or energy-use weights. The value-added weight of a particular industry is the ratio of that industry's value added relative to all the industries; similarly, for the energy weights. Thus both the value-added and energy-use weights sum to one. The base period remains 1967 .

The output-energy ratios are derived by dividing each index of output by total energy consumed (in Btu's), then normalizing to an index base of 100 for 1967. The total energy series is also provided by Marlay.

The relative price of energy (PPI fuels and power/PPI industrial commodities) is based on producer price indexes published by the Bureau of Labor Statistics, U.S. Department of Labor. The capacity utilization index is 
TABLE A.1. Revised Variables Used in Annual Marlay Regressions

\begin{tabular}{|c|c|c|c|c|c|c|c|c|c|}
\hline $\begin{array}{l}\text { YF:S } \\
\mathbf{n x w} \mathbf{x} x \boldsymbol{x}\end{array}$ & 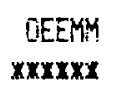 & $\begin{array}{l}\text { OEUM } \\
\mathbf{x \times x \times x \times x}\end{array}$ & 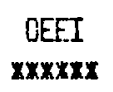 & $\begin{array}{l}\text { OEVI } \\
\mathbf{x x \times x \times x}\end{array}$ & $\begin{array}{l}\text { FELFF: } \\
\mathbf{x \times x \times x}\end{array}$ & 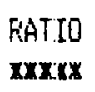 & $\underset{\mathbf{x x x} x \mathbf{x}}{c u}$ & $\begin{array}{l}\text { TIiffe } \\
\mathbf{x x \times x x}\end{array}$ & $\begin{array}{r}T 50 \\
\mathbf{x} \times \mathbf{x} \times \mathbf{x}\end{array}$ \\
\hline 1954 & 89.8 & 89.1 & 93.3 & 93.4 & 1,07 & 1.76 & 80.1 & -13 & 169 \\
\hline 1955 & 92.7 & 88.5 & 95.1 & 92.1 & 1.05 & 1.79 & 87.0 & -12 & 144 \\
\hline 6.5.50 & 92.3 & $88+2$ & 94 & 90.5 & 1.04 & 1.79 & 86.1 & -11 & 121 \\
\hline 1957 & 91.6 & 88.7 & 94.2 & 91.6 & 1.06 & 1.30 & 83.6 & -10 & 100 \\
\hline 1958 & 89.7 & 86.7 & 92.6 & 90.1 & $1+02$ & 1.34 & 75.0 & -9 & 81 \\
\hline 1959 & 95.5 & 92.1 & 96.6 & 94.1 & 1.00 & 1.37 & 81.6 & -8 & 64 \\
\hline 1960 & 93.7 & 90.0 & 94 & 91 & 1.01 & 1.89 & 80.1 & -7 & 49 \\
\hline 1961 & 94.2 & 89.5 & 94.5 & 91 & 1.03 & 1.92 & 77.3 & -6 & 36 \\
\hline 1962 & 96.5 & 92.8 & 96.3 & 93.8 & 1.02 & 1.93 & 81.4 & -5 & 25 \\
\hline 1953 & 97.6 & 93.5 & 97.6 & 94.7 & 1.02 & 1.92 & 83.5 & -4 & 16 \\
\hline 1964 & 98.8 & 93.4 & 97.8 & 93.8 & .99 & 1.90 & 85.7 & -3 & \\
\hline 19.55 & 101.8 & 99.2 & 101 & 98.5 & .99 & 1.85 & 89.5 & -2 & \\
\hline 1966 & $102+1$ & 100.9 & 100.5 & 99.5 & +99 & 1.80 & 91.1 & -1 & \\
\hline 1967 & 100.0 & 100.0 & 100 & 100 & 1,00 & 1,76 & 86.9 & 0 & \\
\hline 1968 & 100.6 & 100.6 & 100.7 & 100.7 & .96 & 1.76 & 87.0 & 1 & 1 \\
\hline 1969 & 102.1 & 100.2 & 101.5 & 99.4 & .95 & $1+76$ & 86.2 & 2 & \\
\hline 1970 & 98.6 & 94.4 & 98 & 93.8 & .97 & 1,77 & 79.2 & 3 & 9 \\
\hline 1971 & 99.8 & 95.8 & 100.1 & 96.3 & 1.01 & $1+78$ & 78.0 & 4 & 16 \\
\hline 1972 & 103.5 & 100.3 & 103.3 & 100.3 & 1.01 & $1+79$ & 83.1 & 5 & 25 \\
\hline 1973 & 105.5 & 103.3 & 104.8 & 102,1 & 1.07 & 1.78 & 87.5 & 6 & 36 \\
\hline 1974 & 107.7 & $105+2$ & 106.1 & 102.2 & 1.35 & 1,76 & 84.2 & 7 & 49 \\
\hline 1975 & 103.7 & 103.1 & 103.6 & 100.6 & 1.43 & 1.75 & 73.6 & 8 & 64 \\
\hline 1976 & 108.3 & 107.2 & $107+9$ & 104.2 & 1.46 & $1+76$ & 80.2 & 9 & 81 \\
\hline 1977 & 110.4 & 111.3 & 109.8 & 107.7 & 1.5 .5 & 1.75 & 82.4 & 10 & 100 \\
\hline 1978 & 115.1 & 116.7 & 114.2 & 112.8 & 1.54 & 1.75 & 84.2 & 11 & 121 \\
\hline 1979 & 117.0 & 120.0 & 110.2 & 109.5 & 1.73 & 1.75 & 85.6 & 12 & 144 \\
\hline 1930 & 115.8 & 120.9 & 108 & 108.8 & 2.07 & 1.76 & 79.8 & 13 & 169 \\
\hline
\end{tabular}


taken directly for FRB publications and is based on the same FRB indexes of industrial production used to construct the indexes of industrial production used in this study. The ratio of new equipment to the stock of equipment is based on the Census of Manufacturers and the Annual Survey of Manufacturers equipment purchases and equipment stocks extended to 1980 based on National Income and Product Account estimates of manufacturing equipment expenditures. The bureaus responsible for generating these figures within the Department of Commerce are Bureau of the Census and Bureau of Economic Analysis, respectively.

The monthly data used in Section 5.0 are shown in Table A.2. IPVMM and IPEMM are the industrial production indexes for manufacturing and mining; the first is the value-added weighted index, the second the Marlay index. ENGY is the monthly industrial use of energy in Btu's. OEVMM, OEEMM, RELPR and CU are as previously defined, but now reported on a monthly basis. One addition, heating degree days (HDD), deserves a reference, while a deletion, the ratio of new to total capital equipment, results from the lack of monthly data for this series. Heating degrees days are measures of the period within a month during which temperatures fell below a norm (65 degrees in this case), requiring home heating. Since the deviation from the norm is used as a weighting factor, more severe cold weather will indicate the need for more heating. Thus, the use of HDD in a monthly analysis should account for both severe weather energy demand shifts and the seasonal use of industrial heating as it affects energy consumption. The HDD data are provided by the National nceanographic and Atmospheric Agency (NOAA). 
TABLE A.2. Revised Variables Used in Monthly Marlay Regressions November 1982

\begin{tabular}{|c|c|c|c|c|c|c|c|c|}
\hline & & & & & & & & \\
\hline 3.01 & 119.4 & 122.3 & 2597 & 04.269 & $91,61 \leqslant$ & 1.0280 & $36 . \overline{3}$ & $9: 3$ \\
\hline 73.12 & 125.3 & 127 & 2 & 108.11 & 205.51 & 1.097 & 87.5 & 795 \\
\hline 73.03 & 125.4 & 138.1 & 236 & 67.45 & 206.31 & 1.0326 & 37.7 & 515 \\
\hline 73.04 & 126.3 & 129.3 & 2391 & 107.81 & & & 37.4 & 364 \\
\hline 73.05 & 127.4 & 131 & 2404 & 105.99 & 103.03 & 1.071 & $37 . ?$ & 190 \\
\hline 73.16 & 120.4 & 132.1 & 2301 & 114.45 & 112.73 & 1.1253 & 97.2 & 2 \\
\hline 73.97 & 122.5 & 17.1 & 2309 & 109.74 & 105.72 & 1.153 & 89 & \\
\hline $73 . \mathrm{sa}$ & $1=6.8$ & $1=0,3$ & $2+17$ & $197+39$ & 104,54 & 1.1217 & 97.6 & \\
\hline 73.39 & $1 \approx 1.3$ & 131.7 & 2312 & $113.7^{4}$ & 113.0 & 1.0726 & 97.0 & 83 \\
\hline 73.10 & 132.7 & 134.1 & 2584 & 103.46 & 192.33 & $1.3 \exists 4$ & 87.7 & 217 \\
\hline 73.14 & 130.4 & 132.5 & $2 \leq 18$ & 99,756 & 98.23 & 1.176 & 37.7 & 510 \\
\hline 73.12 & 123.2 & 19.7 & 2733 & 03.598 & 99.828 & 1.146 & 37.3 & 820 \\
\hline 74.01 & 122.7 & 126.5 & 24.46 & 103.1 & 100.12 & 1.231 & 85.8 & 952 \\
\hline 74.02 & 126.8 & 129 & 2338 & 109,15 & 108.87 & 1.2336 & 85.3 & 77 \\
\hline 74.83 & 128 & 130.1 & 2986 & 108.71 & 106.7 & 1.2272 & 85.4 & 55 \\
\hline 74,34 & 127.4 & 131.5 & 2195 & 119,44 & 115. d6 & 1.3499 & 35.1 & 316 \\
\hline 74.35 & 139 & & 314 & $114=9$ & i1:.J9? & 1.375 & t. & 176 \\
\hline $74+16$ & 132.2 & 135 & 221 & $121 .: 8$ & $: 13.51$ & $1.373^{4}$ & 85.7 & 44 \\
\hline 74.37 & 123.5 & $123+4$ & 350 & 108.53 & 194.72 & 1.4149 & 5.4 & \\
\hline 74,33 & 127.5 & 120.4 & 2378 & 103.41 & 1.25 .75 & 1.3785 & 35.1 & $i^{2}$ \\
\hline 74.19 & 132.1 & 131.9 & 2392 & 109.93 & 120.05 & $\therefore .312$ & 94.3 & 100 \\
\hline 74.10 & $1 \equiv 0.4$ & 132.4 & 2597 & 101.64 & 100,06 & 1.3965 & 82,7 & 314 \\
\hline 74.11 & 122.4 & 125.2 & 2570 & 97.121 & 94,905 & 1.3725 & 79.5 & 500 \\
\hline 74.12 & 110.5 & 115.6 & 2539 & 90.769 & 86.724 & 1.3737 & 75.1 & 313 \\
\hline 75.01 & 107.4 & & 33 & 88.571 & 34.291 & 1.3363 & 71.9 & 843 \\
\hline 75.02 & 108.8 & 112.6 & 2105 & 106.64 & 103 & 1.3795 & 70.1 & 764 \\
\hline 75.03 & 107.7 & 130.5 & 2222 & 99.143 & 96.586 & 1.3714 & 39 & 796 \\
\hline$\pi, 04$ & 109.4 & $1+3$ & 1906 & 116.42 & 114.38 & 1.3736 & 39.9 & 459 \\
\hline 75.05 & 110.5 & 1. & 1969 & 112.39 & $1: 1$. & $1 .+122$ & 70.3 & $: 18$ \\
\hline E.16 & $: 15.5$ & $1: 3.3$ & 2304 & 113.21 & 114.35 & 1.120 & 71.7 & 36 \\
\hline 7.07 & 109.7 & 09.4 & 2180 & 194.36 & 105.99 & $1,+494$ & 73.3 & \\
\hline 75.08 & 117.1 & 5.6 & 2136 & 106.4 & 507.73 & 1.7 .557 & 74.8 & 12 \\
\hline 75.09 & 122.4 & 119,6 & 2134 & 111.73 & $114+3$ & 1.4726 & 75.7 & 106 \\
\hline 75.10 & 122.7 & 121.4 & 2402 & 100.76 & 101.79 & 1.4582 & 75.5 & 241 \\
\hline 7.11 & 120.7 & 20.7 & 2401 & 100.22 & 100.17 & 1.4 .552 & 76.2 & 471 \\
\hline 75.12 & 115.8 & & 2581 & 90.528 & 39.405 & $1,4.551$ & 76.6 & 326 \\
\hline 75.01 & 117.7 & 118.3 & 2473 & 95.176 & 74.549 & i. 4512 & $\pi .5$ & 1003 \\
\hline 76.12 & 124.9 & 125 & 2143 & 116.20 & 116.14 & 1.4 .755 & 78.8 & \pm 27 \\
\hline $76+03$ & 125.7 & 127.1 & 233 & 113.47 & 112.17 & $1.4: 93$ & 79 & 500 \\
\hline 76.04 & 126 & 129.7 & 2113 & 12.09 & $\$ 18.83$ & 1.472 & $70 . i$ & 314 \\
\hline 76.05 & 127.7 & & 239 & 117.92 & 115. & 1.4 .25 & 79.6 & 105 \\
\hline 76.86 & 130.9 & 2.7 & 2212 & 119.6 & 117.92 & 1.407 & 79.7 & 27 \\
\hline 76.07 & 122.7 & 175.8 & 2074 & 110.29 & 107.52 & $1.4: 513$ & 30.1 & \\
\hline 76.98 & 128.5 & 130. & 2309 & 112.76 & $110 . \bar{y}$ & $1,4.576$ & 80.1 & \\
\hline 76.19 & 131.5 & & 2246 & 116.1 & $11 t$ & $1.4: 5 \pi$ & 79.8 & 35 \\
\hline 76.19 & $13 \hat{k}, 1$ & 131.7 & 2515 & 100.41 & $\$ 00.60$ & 1.494 & 79.5 & 52 \\
\hline 76.11 & 129.9 & $1=9.9$ & 2630 & 90.158 & 96.422 & 1.5151 & $80 . i$ & $57:$ \\
\hline & & & & & 79.296 & 14069 & $=$ & $97 n$ \\
\hline
\end{tabular}


TABLE A.2. (Contd)

\begin{tabular}{|c|c|c|c|c|c|c|c|c|}
\hline 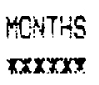 & $\begin{array}{l}\text { IFUny } \\
\text { :xxrix }\end{array}$ & $\begin{array}{l}\text { IFEMY } \\
\text { xrmxxx }\end{array}$ & $\begin{array}{l}\text { E) } \\
\mathbf{x} \mathbf{x} \times \mathbf{x}\end{array}$ & 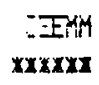 & 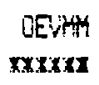 & 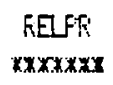 & xxxxx & $\begin{array}{c}H C D \\
\mathbf{x x z x x}\end{array}$ \\
\hline 77.01 & 125.1 & 133.9 & 2630 & 93.9 & 94,3 & 1.4993 & 30.2 & 1224 \\
\hline 77.12 & 130.6 & 129.1 & 2047 & 135.7 & 127.1 & $1.524 \%$ & 30.7 & 776 \\
\hline 77.03 & 133.3 & 133.3 & 2357 & 113.2 & 112.7 & 1.5321 & $81, \overline{5}$ & 542 \\
\hline 77,34 & 134.2 & 136,1 & 2213 & 122,6 & 120.8 & 1.5458 & 81.7 & 276 \\
\hline 7.35 & 135.4 & 137.8 & 2358 & 115.0 & 113.0 & 1.5566 & 32.1 & 118 \\
\hline$\pi 7.06$ & 139.7 & 138.7 & 2371 & 116.7 & 117.2 & 1.5622 & & 38 \\
\hline 77.07 & $\$ 30.7$ & 131.6 & $23^{4} 1$ & 112.1 & 111.3 & 1.5699 & 22.5 & \\
\hline 77.08 & 135.8 & 134.2 & 2075 & 112.2 & 113.0 & 1.519 & 82.4 & 14 \\
\hline 77.09 & 140.6 & 134,9 & 2414 & 111.4 & 116.1 & $1, \approx 057$ & 82,4 & o1 \\
\hline 77.10 & 141.9 & 137.7 & 2542 & 108.2 & 111.2 & 1.56 & 82.6 & 306 \\
\hline 77.11 & $\$ 38.3$ & 135. & 2601 & 103.5 & 106.1 & $1,5=8$ & 32.5 & 508 \\
\hline 7.12 & $132+6$ & 131.1 & 773 & 95.3 & 96.7 & 1.56 & 82.6 & 871 \\
\hline 79.01 & 130.7 & 129.7 & 2706 & 95.6 & 96.2 & 1.5516 & 81.7 & 1094 \\
\hline 79.12 & 136.2 & 131.9 & 2238 & 117.5 & 121.3 & 1.5421 & 81.7 & 999 \\
\hline 79.03 & 138.9 & 135.7 & 2242 & 120.7 & 123.5 & 1.5448 & 82.7 & 703 \\
\hline 78.04 & 142.7 & 141.2 & 2243 & 125.5 & 126.8 & 1.5403 & 93.8 & 357 \\
\hline 78.15 & 142.5 & 143,1 & 2400 & 118.5 & 117.9 & 1.3715 & 93.8 & 162 \\
\hline 79.16 & 147.1 & 155.7 & 2219 & 125.5 & 126.5 & 1.5436 & 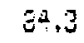 & 31 \\
\hline 75.37 & 133.7 & 139.0 & 2396 & 115.7 & $115 .+$ & 1.5433 & 24,8 & 2 \\
\hline 79.08 & 145.0 & 142.6 & $241:$ & $\$ 17,9$ & 119.3 & $1,5=69$ & $5=2$ & 11 \\
\hline 78.09 & 150.9 & 145.7 & 2357 & 123.4 & 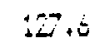 & $1.5 \bigcirc 74$ & EE.5 & 61 \\
\hline 79.10 & 152.4 & $1+7.8$ & 2579 & 114.3 & 117.8 & 1.53 & 30.3 & 295 \\
\hline 79.11 & 149.5 & 146,9 & 2637 & 111.1 & 113,0 & 1.5254 & 86.3 & 531 \\
\hline 70.12 & 144.8 & 144.3 & 2782 & 193.4 & 103.7 & $1.539 !$ & 96.3 & 857 \\
\hline 79.01 & 141.7 & 129.5 & 2919 & 94.6 & 96.9 & 1.5358 & 86.6 & 1109 \\
\hline 79,02 & 148.2 & 142,2 & 2480 & 114.3 & $119+1$ & $1.5=93$ & 36.8 & 991 \\
\hline 79.03 & 151.2 & 146.3 & 2533 & 115.1 & 118.9 & 1.5571 & 87.2 & 593 \\
\hline 79.14 & 148.3 & 147.9 & 2391 & 123.3 & 123.6 & 1.5831 & SE. 3 & 375 \\
\hline 79.05 & 150.5 & 148.0 & 2581 & 114.3 & 116.2 & 1.5326 & 86.3 & 154 \\
\hline 79.16 & 154.6 & 150.4 & 2497 & $i 20.1$ & 123.4 & 1.6825 & 36.1 & 39 \\
\hline 79.07 & 145.4 & 143.7 & 2530 & 113.2 & $114+5$ & 1.7346 & 86.7 & 7 \\
\hline 77.18 & 150.0 & 176.9 & 2592 & 113.4 & 155.3 & 1.7799 & 54.9 & 15 \\
\hline 79.09 & 155.6 & 148.0 & 2477 & 119.1 & 125.2 & 1.0524 & 35.2 & 62 \\
\hline 79.10 & 156.1 & 148.3 & 2766 & $107+2$ & 112,5 & 1.3695 & 84.8 & 282 \\
\hline 79.11 & 152.2 & 147.6 & 2783 & & 109.0 & 1.3542 & 84.4 & 542 \\
\hline 79.12 & 146.3 & 144.5 & 2856 & 100.9 & 102.1 & 1.872 & 54.1 & $T i 0$ \\
\hline 80.01 & 142.8 & 141.7 & 2892 & 97,7 & 98.4 & 1.9105 & 84,0 & 914 \\
\hline 80.02 & 148.1 & 144.2 & 2592 & 110.9 & 113.9 & 1.9932 & 83.6 & 960 \\
\hline 80.03 & 149.1 & 145.3 & 2636 & 109,9 & 112.7 & 2.0447 & 82.7 & 702 \\
\hline 80.04 & 14.97 & 142.1 & 2347 & 120.7 & 122,9 & 2. J881 & 30.3 & 348 \\
\hline 30.05 & 140.7 & 136.3 & 2407 & 113.3 & 116.5 & 2.3949 & 77.6 & 145 \\
\hline 90.06 & 142.8 & 135.0 & 2306 & 116.7 & 122.7 & 2.0556 & 75.7 & E0 \\
\hline 30.07 & 132.8 & 124.6 & 2238 & 109.5 & 116.7 & 2.1642 & 74,9 & 5 \\
\hline 89.08 & 140.0 & 299.6 & 2216 & 116.6 & $125+9$ & 2.1134 & 75.3 & $?$ \\
\hline 30.09 & 147,4 & 135.6 & 2339 & 115.6 & 125.6 & 2.1046 & 77,0 & 50 \\
\hline 90.10 & 150.7 & $1+0.7$ & $2 \leq 29$ & 106.8 & 114.2 & 2.0521 & 70.2 & 329 \\
\hline 80.11 & 150.6 & 143.3 & 2679 & 106.6 & 112.0 & 2.0542 & 79.3 & 531 \\
\hline 90.12 & 146.7 & 141.8 & 313 & 200.3 & 103.7 & 2.1122 & 79.3 & 83 \\
\hline
\end{tabular}




\section{DISTRIBUTION}

No. of

Copies

\section{OFFSITE}

10 Robert Marlay

U.S. Department of Energy

Office of Policy, Planning and Analys is

Forrestal Building

1000 Independence Avenue

Washington, DC 20585

Fred Abe 1

U.S. Department of Energy

Office of Building Enerqy Research and Development

Forrestal Building

1000 Independence Avenue

Washington, DC 20585

Peter Back

U.S. Department of Energy

Office of Alcohol Fuels

Forrestal Building

1000 Indedendence Avenue

Washington, DC 20585

Harvey Major

U.S. Department of Energy

Office of Policy, Planning and

Analys is

Forrestal Building, 6B-052

1000 Independence Avenue

Washington, DC 20585

Maxine Savitz

U.S. Department of Energy

Deputy Assistant Secretary for Conservation

Forrestal Building

1000 Independence Avenue

Washington, DC 20585
No. of

Copies

Bill White

U.S. Department of Energy

Office of Policy, Planning and

Evaluation

Forresta 1 Building

1000 Independence Avenue

Washington, DC 20585

27 DOE Technical Information Center

Eric Hirst

Oak Ridge National Laboratory

P.0. Box $X$

Oak Ridge, TN 37830

Lee Schipper

Lawrence Berkeley Laboratory

1 Cyclotron Road

Berkeley, CA 94720

David 0. Wood

Energy Laboratory

MIT

Cambridge, MA 02139

ONSITE

DOE - Richland Operations

H. E. Ransom

29 Pacific Northwest Laboratory

W. B. Ashton

D. B. Belzer

J. M. Callaway

J. W. Currie

J. E. Danko

M. J. King

R. G. Rivera

J. M. Roop (12)

Economics Library (3)

Publishing Coordination (2)

Technical Information Files (5) 
i

1 